\title{
House Prices, Borrowing Constraints and Monetary Policy in the Business Cycle
}

\author{
Matteo Iacoviello* \\ Boston College
}

December 6, 2004

\begin{abstract}
I develop and estimate a monetary business cycle model with nominal loans and collateral constraints tied to housing values. Demand shocks move together housing and nominal prices, and are amplified and propagated over time. The financial accelerator is not uniform: nominal debt dampens supply shocks, stabilizing the economy under interest rate control. Structural estimation supports two key model features: collateral effects dramatically improve the response of aggregate demand to house prices shocks; nominal debt improves the sluggish response of output to inflation surprises. Finally, policy evaluation considers the role of house prices and debt indexation in affecting monetary policy trade-offs.
\end{abstract} (JEL E31, E32, E44, E52, R21)

*Department of Economics, Boston College, Chestnut Hill, MA 02467, USA (email: iacoviel@bc.edu). I am deeply indebted to my Ph.D. advisor at the London School of Economics, Nobuhiro Kiyotaki, for his continuous help and invaluable advice. I thank Fabio Canova, Raffaella Giacomini, Christopher House, Peter Ireland, Raoul Minetti, François Ortalo-Magné, Marina Pavan, Christopher Pissarides, Fabio Schiantarelli, two anonymous referees and seminar participants at the Bank of England, Boston College, the European Central Bank, the Ente Luigi Einaudi, the Federal Reserve Bank of New York, the Federal Reserve Bank of St.Louis, the London School of Economics, the NBER Monetary Economics Meeting and Northeastern University for their helpful comments on various versions of this work. Viktors Stebunovs provided superb research assistance. 
The population is not distributed between debtors and creditors randomly. Debtors have borrowed for good reasons, most of which indicate a high marginal propensity to spend from wealth or from current income or from any other liquid resources they can command. Typically their indebtedness is rationed by lenders [...]. Business borrowers typically have a strong propensity to hold physical capital [...]. Their desired portfolios contain more capital than their net worth [...]. Household debtors are frequently young families acquiring homes and furnishings before they earn incomes to pay for them outright; given the difficulty of borrowing against future wages, they are liquidity-constrained and have a high marginal propensity to consume.

James Tobin, Asset Accumulation and Economic Activity, 1980 p.10.

A long tradition in economics, starting with Irving Fisher's (1933) debt-deflation explanation of the Great Depression, considers financial factors as key elements of business cycles. In this view, deteriorating credit market conditions, like growing debt burdens and falling asset prices, are not just passive reflections of a declining economy, but are themselves a major factor depressing economic activity.

Although this "credit view" has a long history, most of theoretical work on this subject has been partial equilibrium in nature until the late 1980s, when Ben Bernanke and Mark Gertler (1989) formalized these ideas in a general equilibrium framework. Following their work, various authors have presented dynamic models in which financing frictions on the firm side may amplify or propagate output fluctuations in response to aggregate disturbances: examples include the real models of Nobuhiro Kiyotaki and John Moore (1997) and Charles Carlstrom and Timothy Fuerst (1997), and the sticky-price model of Bernanke, Gertler and Simon Gilchrist (1999). Empirically, various studies have shown that firms' investment decisions are sensitive to various measures of firms' net worth (see Glenn Hubbard, 1998, for a review). At the same time, evidence of financing constraints at the household level has been widely documented by Stephen Zeldes (1989), Tullio Jappelli and Marco Pagano (1989), John Campbell and Gregory Mankiw (1989) and Christopher Carroll and Wendy Dunn (1997).

While these studies have highlighted the importance of financial factors for macroeconomic fluctua- 
tions, to date there has been no systematic evaluation of the extent to which a general equilibrium model with financial frictions can explain the aggregate time-series evidence on the one hand, and be used for monetary policy analysis on the other. This is the perspective adopted here. From the modeling point of view, my starting point is a variant of the Bernanke, Gertler and Gilchrist (1999) new-Keynesian setup in which endogenous variations in the balance sheet of the firms generate a "financial accelerator" by enhancing the amplitude of business cycles. To this framework, I add two main features: (1) collateral constraints tied to real estate values for firms, as in Kiyotaki and Moore (1997), and for a subset of the households; (2) nominal debt. The reason for housing ${ }^{1}$ collateral is practical and substantial: practical because, empirically, a large proportion of borrowing is secured by real estate; substantial because, although housing markets seem to play a role in business fluctuations, ${ }^{2}$ the channels by which they affect the economy are far from being understood. The reason for having nominal debt comes from the widespread observation that, in low inflation countries, almost all debt contracts are in nominal terms, even if they appear hard to justify on welfare-theoretic grounds: understanding their implications for macroeconomic outcomes is therefore a crucial task.

In addition, I ask whether the model is able to explain both key business cycle facts and the interaction between asset prices and economic activity. To this end, I estimate the key structural parameters by minimizing the distance between the impulse responses implied by the model and those generated by an unrestricted Vector Autoregression. The estimates are both economically plausible and statistically significant. They also provide support for the two main features of the model (collateral constraints and nominal debt). In the concluding part of the paper, therefore, I use the estimated model for quantitative policy analysis.

The model transmission mechanism works as follows. Consider, for sake of argument, a positive demand shock. When demand rises, consumer and asset prices increase: the rise in asset prices increases the borrowing capacity of the debtors, allowing them to spend and invest more. The rise in consumer prices reduces the real value of their outstanding debt obligations, positively affecting their net worth. Given that borrowers have a higher propensity to spend than lenders, the net effect on demand is positive, and acts as a powerful amplification mechanism. However, while it amplifies the demand 
shocks, consumer price inflation dampens the shocks that induce a negative correlation between output and inflation: for instance, adverse supply shocks are beneficial to borrowers' net worth if obligations are held in nominal terms. Hence, unlike the previous papers, the financial accelerator really depends on where the shocks come from: the model features an accelerator of demand shocks, and a "decelerator" of supply shocks.

The transmission mechanism described above is at the root of the model success in explaining two salient features of the data. First, collateral effects on the firm and the household side allow matching the positive response of spending to a house price shock. ${ }^{3}$ Second, nominal debt can replicate the humpshaped dynamics of spending to an inflation shock. ${ }^{4}$ Such improvements in the model ability to reflect short-run dynamic properties are especially important, given that several studies (e.g. Jordi Galí, 2004, and Peter Ireland, 2004b) have stressed the role of non-technology and non-monetary disturbances for understanding business fluctuations.

Finally, I address and answer two important policy questions. First, I find that allowing the monetary authority to respond to asset prices yields negligible gains in terms of output and inflation stabilization. Second, I find that nominal (vis-à-vis indexed) debt yields an improved output-inflation variance tradeoff for the central bank: this happens because the sources of trade-offs in the model do not get amplified, since such shocks, ceteris paribus, transfer resources from lenders to borrowers during a downturn.

The plan of the paper is as follows. The next section presents some VAR evidence on house prices and the business cycle. Section II presents the basic model. Section III extends the basic model by including a constrained household sector and by allowing for variable capital. Section IV estimates the structural parameters of the model. Section V analyses its dynamics. Section VI looks at house prices and debt indexation for the formulation of systematic monetary policy. Concluding remarks are in Section VII.

\section{VAR evidence on house prices and the business cycle}

Figure 1 presents impulse responses (with 95 percent bootstrapped confidence bands) from a VAR with detrended real GDP $(Y)$, change in the log of GDP deflator $(\pi)$, detrended real house prices $(q)$, and Fed Funds rate $(R)$ from 1974Q1 to 2003Q2. ${ }^{5}$ I use this VAR to document the key relationships in the 
data, and, later in the paper, to choose the parameters of the extended model in a way to match the VAR impulse responses.

Here and in the rest of the paper, the variables are expressed in percentages and in quarterly rates. The shocks are orthogonalized in the order $R, \pi, q$ and $Y$. The ordering did not affect the results substantially: as I will show below, such an ordering also renders the VAR and the model more directly comparable. The results suggest that a model of the interaction between house prices and the business cycle has to deliver:

1) A negative response of nominal prices, real house prices and GDP to tight money (Figure 1, first row);

2) A significant negative response of real house prices and a negative but small response of output to a positive inflation disturbance (second row);

3) A positive comovement of asset prices and output in response to asset price shocks (third row) and to output shocks (fourth row). Taken together, the two rows highlight a two-way interaction between house prices and output.

In the rest of this paper, I develop and estimate a model that is consistent with these facts and that can be used for policy analysis. I start with a basic model, which conveys the intuition.

\section{The basic model}

Consider a discrete time, infinite horizon economy, populated by entrepreneurs and patient households, infinitely lived and of measure one. The term "patient" captures the assumption that households have lower discount rates than firms and distinguishes this group from the impatient households of the extended model (next section). Entrepreneurs produce a homogeneous good, hiring household labor and combining it with collateralizable real estate. Households consume, work, demand real estate and money. In addition, there are retailers and a central bank. Retailers are the source of nominal rigidity. The central bank adjusts money supply and transfers to support an interest rate rule.

In order to have effects on economic activity from shifts in asset holdings, I allow housing investment by both sectors. However, I assume that real estate is fixed in the aggregate, which guarantees a variable 
price of housing. This assumption is not crucial to the propagation mechanism: I will show below that collateral effects can generate sizeable amplification even when the share of real estate in production is small.

As their activities are somewhat conventional, I start with the patient households' problem.

A. Patient households. The household sector (denoted with a prime) is standard, with the exception of housing (services) in the utility function. ${ }^{6}$

Households maximize a lifetime utility function given by

$$
E_{0} \sum_{t=0}^{\infty} \beta^{t}\left(\ln c_{t}^{\prime}+j \ln h_{t}^{\prime}-\left(L_{t}^{\prime}\right)^{\eta} / \eta+\chi \ln \left(M_{t}^{\prime} / P_{t}\right)\right)
$$

where $E_{0}$ is the expectation operator, $\beta \in(0,1)$ is the discount factor, $c_{t}^{\prime}$ is consumption at $t, h_{t}^{\prime}$ denotes the holdings of housing, $L_{t}^{\prime}$ are hours of work (households work for the entrepreneurs) and $M_{t}^{\prime} / P_{t}$ are money balances divided by the price level. Denote with $q_{t} \equiv Q_{t} / P_{t}$ the real housing price, with $w_{t}^{\prime} \equiv W_{t}^{\prime} / P_{t}$ the real wage. Assume that households lend in real terms $-b_{t}^{\prime}$ (or borrow $b_{t}^{\prime} \equiv B_{t}^{\prime} / P_{t}$ ) and receive back $-R_{t-1} B_{t-1}^{\prime} / P_{t}$, where $R_{t-1}$ is the nominal interest rate on loans between $t-1$ and $t$, so that obligations are set in money terms. Denoting with $\Delta$ the first difference operator, the flow of funds is

$$
c_{t}^{\prime}+q_{t} \Delta h_{t}^{\prime}+R_{t-1} b_{t-1}^{\prime} / \pi_{t}=b_{t}^{\prime}+w_{t}^{\prime} L_{t}^{\prime}+F_{t}+T_{t}^{\prime}-\Delta M_{t}^{\prime} / P_{t}
$$

where $\pi_{t} \equiv P_{t} / P_{t-1}$ denotes the gross inflation rate, $F_{t}$ are lump-sum profits received from the retailers (described below) and the last two terms are net transfers from the central bank that are financed by printing money. Solving this problem yields first order conditions for consumption (2), labor supply (3) and housing demand (4):

$$
\begin{aligned}
\frac{1}{c_{t}^{\prime}} & =\beta E_{t}\left(\frac{R_{t}}{\pi_{t+1} c_{t+1}^{\prime}}\right) \\
w_{t}^{\prime} & =\left(L_{t}^{\prime}\right)^{\eta-1} / c_{t}^{\prime} \\
\frac{q_{t}}{c_{t}^{\prime}} & =\frac{j}{h_{t}^{\prime}}+\beta E_{t}\left(\frac{q_{t+1}}{c_{t+1}^{\prime}}\right) .
\end{aligned}
$$

The first-order condition with respect to $M_{t}^{\prime} / P_{t}$ yields a standard money demand equation. Since I focus in what follows on interest rates rules, money supply will always meet money demand at the desired 
equilibrium nominal interest rate. As utility is separable in money balances, the quantity of money has no implications for the rest of the model, and can be ignored.

B. Entrepreneurs. Entrepreneurs use a Cobb-Douglas constant returns to scale technology that uses real estate and labor as inputs. They produce an intermediate good $Y_{t}$ according to:

$$
Y_{t}=A\left(h_{t-1}\right)^{\nu}\left(L_{t}\right)^{1-\nu}
$$

where $A$ is the technology parameter, $h$ is real estate input, $L$ is the labor input. Output cannot be immediately transformed into consumption $c_{t}$ : following Bernanke, Gertler and Gilchrist (1999), I assume that retailers purchase the intermediate good from entrepreneurs at the wholesale price $P_{t}^{w}$ and transform it into a composite final good, whose price index is $P_{t}$. With this notation, $X_{t} \equiv P_{t} / P_{t}^{w}$ denotes the markup of final over intermediate goods.

As in Kiyotaki and Moore (1997), I assume a limit on the obligations of the entrepreneurs. Suppose that, if borrowers repudiate their debt obligations, the lenders can repossess the borrowers' assets by paying a proportional transaction cost $(1-m) E_{t}\left(q_{t+1} h_{t}\right)$. In this case the maximum amount $B_{t}$ that a creditor can borrow is bound by $m E_{t}\left(Q_{t+1} h_{t} / R_{t}\right)$. In real terms:

$$
b_{t} \leq m E_{t}\left(q_{t+1} h_{t} \pi_{t+1} / R_{t}\right)
$$

To make matters interesting, one wants a steady state in which the entrepreneurial return to savings is greater than the interest rate, which implies a binding borrowing constraint. At the same time, one has to ensure that entrepreneurs will not postpone consumption and quickly accumulate wealth so that they are completely self-financed and the borrowing constraint becomes non binding. To deal with this problem, I assume that entrepreneurs discount the future more heavily than households. They maximize

$$
E_{0} \sum_{t=0}^{\infty} \gamma^{t} \ln c_{t}
$$

where $\gamma<\beta,{ }^{7}$ subject to the technology constraint, the borrowing constraint and the following flow of funds:

$$
Y_{t} / X_{t}+b_{t}=c_{t}+q_{t} \Delta h_{t}+R_{t-1} b_{t-1} / \pi_{t}+w_{t}^{\prime} L_{t}
$$


where $R_{t-1} b_{t-1} / \pi_{t}$ in (6) reflects the assumption that debt contracts are set in nominal terms, so that price changes between $t-1$ and $t$ can affect the realized real interest rate. I use this assumption on empirical grounds: in low-inflation countries, almost all debt contracts are set in nominal terms. ${ }^{8}$

Define $\lambda_{t}$ as the time $t$ shadow value of the borrowing constraint. The first-order conditions for an optimum are the consumption Euler equation, real estate demand and labor demand:

$$
\begin{aligned}
\frac{1}{c_{t}} & =E_{t}\left(\frac{\gamma R_{t}}{\pi_{t+1} c_{t+1}}\right)+\lambda_{t} R_{t} \\
\frac{1}{c_{t}} q_{t} & =E_{t}\left(\frac{\gamma}{c_{t+1}}\left(\nu \frac{Y_{t+1}}{X_{t+1} h_{t}}+q_{t+1}\right)+\lambda_{t} m \pi_{t+1} q_{t+1}\right) \\
w_{t}^{\prime} & =(1-\nu) Y_{t} /\left(X_{t} L_{t}\right) .
\end{aligned}
$$

Both the Euler and the housing demand equations differ from the usual formulations because of the presence of $\lambda_{t}$, the Lagrange multiplier on the borrowing constraint. $\lambda_{t}$ equals the increase in lifetime utility that would stem from borrowing $R_{t}$ dollars, consuming (equation 7 ) or investing (equation 8) the proceeds, and reducing consumption by an appropriate amount next period.

Without uncertainty, the assumption $\gamma<\beta$ guarantees that entrepreneurs are constrained in and around the steady state. In fact, the steady state consumption Euler equation for the household implies, with zero inflation, that $R=1 / \beta$, the household time preference rate. Combining this result with the steady state entrepreneurial Euler equation for consumption yields: $\lambda=(\beta-\gamma) / c>0$. Therefore, the borrowing constraint will hold with equality:

$$
b_{t}=m E_{t}\left(q_{t+1} h_{t} \pi_{t+1} / R_{t}\right) .
$$

Matters are of course thornier when there is uncertainty. The concavity of the objective function implies in fact that, in some states of the world, entrepreneurs might "self-insure" by borrowing less than their credit limit so as to buffer their consumption against adverse shocks. That is, there is some target level of their net worth such that, if their actual net worth falls short of that target, the precautionary saving motive might outweigh impatience and entrepreneurs will try to restore some assets, borrowing less than the limit. Specifically, entrepreneurs might not hit the borrowing limit after a sufficiently long run of positive shocks. In this case, the model would become asymmetric around its stationary state. In bad times entrepreneurs would be constrained; in good times, they might be unconstrained. In such 
a case, a linear approximation around the deterministic steady state might give misleading results. In the paper, I take as given that uncertainty is "small enough" relative to degree of impatience so as to rule out this possibility. In Appendix C, I present evidence from non-linear simulations that backs this assumption. ${ }^{9}$

C. Retailers. To motivate sticky prices I assume implicit costs of adjusting nominal prices and, as in Bernanke, Gertler and Gilchrist (1999), monopolistic competition at the retail level. A continuum of retailers of mass 1 , indexed by $z$, buy intermediate goods $Y_{t}$ from entrepreneurs at $P_{t}^{w}$ in a competitive market, differentiate the goods at no cost into $Y_{t}(z)$ and sell $Y_{t}(z)$ at the price $P_{t}(z)$. Final goods are $Y_{t}^{f}=\left(\int_{0}^{1} Y_{t}(z)^{\frac{\varepsilon-1}{\varepsilon}} d z\right)^{\frac{\varepsilon}{\varepsilon-1}}$ where $\varepsilon>1$. Given this aggregate output index, ${ }^{10}$ the price index is $P_{t}=$ $\left(\int_{0}^{1} P_{t}(z)^{1-\varepsilon} d z\right)^{\frac{1}{1-\varepsilon}}$, so that each retailer faces an individual demand curve of $Y_{t}(z)=\left(P_{t}(z) / P_{t}\right)^{-\varepsilon} Y_{t}^{f}$.

Each retailer chooses a sale price $P_{t}(z)$ taking $P_{t}^{w}$ and the demand curve as given. The sale price can be changed in every period only with probability $1-\theta$. Denote with $P_{t}^{*}(z)$ the "reset" price and with $Y_{t+k}^{*}(z)=\left(P_{t}^{*}(z) / P_{t+k}\right)^{-\varepsilon} Y_{t+k}$ the corresponding demand. The optimal $P_{t}^{*}(z)$ solves:

$$
\sum_{k=0}^{\infty} \theta^{k} E_{t}\left\{\Lambda_{t, k}\left(\frac{P_{t}^{*}(z)}{P_{t+k}}-\frac{X}{X_{t+k}}\right) Y_{t+k}^{*}(z)\right\}=0
$$

where $\Lambda_{t, k}=\beta\left(c_{t}^{\prime} / c_{t+k}^{\prime}\right)$ is the patient household relevant discount factor and $X_{t}$ is the markup, which in steady state equals $X=\varepsilon /(\varepsilon-1)$. This condition states that $P_{t}^{*}$ equates expected discounted marginal revenue to expected discounted marginal cost. Profits $F_{t}=\left(1-1 / X_{t}\right) Y_{t}$ are finally rebated to patient households.

As a fraction $\theta$ of prices stays unchanged, the aggregate price level evolution is

$$
P_{t}=\left(\theta P_{t-1}^{\varepsilon}+(1-\theta)\left(P_{t}^{*}\right)^{1-\varepsilon}\right)^{1 /(1-\varepsilon)} .
$$

Combining (11) and (12) and linearizing yields a forward-looking Phillips curve, which states that inflation depends positively on expected inflation and negatively on the markup $X_{t}$ of final over intermediate goods. 
D. Central bank policy and the interest rate rule. The central bank makes lump sum transfers of money to the real sector to implement a Taylor-type interest rate rule. The rule takes the form

$$
R_{t}=\left(R_{t-1}\right)^{r_{R}}\left(\pi_{t-1}^{1+r_{\pi}}\left(Y_{t-1} / Y\right)^{r_{Y}} \overline{r r}\right)^{1-r_{R}} e_{R, t}
$$

where $\overline{r r}$ and $Y$ are steady state real rate and output, respectively. Here, monetary policy responds systematically to past inflation and past output. ${ }^{11}$ If $r_{R}>0$, the rule allows for interest rate inertia. $e_{R, t}$ is a white noise shock process with zero mean and variance $\sigma_{e}^{2}$.

E. Equilibrium. Absent shocks, the model has a unique stationary equilibrium in which the entrepreneurs hit the borrowing constraint and borrow up to the limit, making the interest payments on the debt and rolling the steady state stock of debt over forever. The equilibrium is an allocation $\left\{h_{t}, h_{t}^{\prime}, L_{t}, L_{t}^{\prime}, Y_{t}, c_{t}, c_{t}^{\prime}, b_{t}, b_{t}^{\prime}\right\}_{t=0}^{\infty}$ together with the sequence of values $\left\{w_{t}^{\prime}, R_{t}, P_{t}, P_{t}^{*}, X_{t}, \lambda_{t}, q_{t}\right\}_{t=0}^{\infty}$ satisfying equations (2) to (13) and the market clearing conditions for labor $\left(L_{t}=L_{t}^{\prime}\right)$, real estate $\left(h_{t}+h_{t}^{\prime}=H\right)$, goods $\left(c_{t}+c_{t}^{\prime}=Y_{t}\right)$, and loans $\left(b_{t}+b_{t}^{\prime}=0\right)$, given $\left\{h_{t-1}, R_{t-1}, b_{t-1}, P_{t-1}\right\}$ and the sequence of monetary shocks $\left\{e_{R, t}\right\}$, together with the relevant transversality conditions.

Appendix A describes the steady state. Let hatted variables denote percent changes from the steady state, and those without subscript denote steady state values. The model can be reduced to the following linearized system (which I solve numerically using the methods described by Harald Uhlig (1999)):

$$
\begin{gathered}
\widehat{Y}_{t}=(c / Y) \widehat{c}_{t}+\left(c^{\prime} / Y\right) \widehat{c}_{t}^{\prime} \\
\widehat{c}_{t}^{\prime}=E_{t} \widehat{c}_{t+1}^{\prime}-\widehat{r r}_{t} \\
c \widehat{c}_{t}=b \widehat{b}_{t}+R b\left(\widehat{\pi}_{t}-\widehat{R}_{t-1}-\widehat{b}_{t-1}\right)+(\nu Y / X)\left(\widehat{Y}_{t}-\widehat{X}_{t}\right)-q h \Delta \widehat{h}_{t} \\
\widehat{q}_{t}=\gamma_{e} E_{t} \widehat{q}_{t+1}+\left(1-\gamma_{e}\right) E_{t}\left(\widehat{Y}_{t+1}-\widehat{h}_{t}-\widehat{X}_{t+1}\right)-m \beta \widehat{r r}_{t}-(1-m \beta) E_{t} \Delta \widehat{c}_{t+1} \\
\widehat{q}_{t}=\beta E_{t} \widehat{q}_{t+1}+\iota \widehat{h}_{t}+\widehat{c}_{t}^{\prime}-\beta E_{t} \widehat{c}_{t+1}^{\prime} \\
\widehat{b}_{t}=E_{t} \widehat{q}_{t+1}+\widehat{h}_{t}-\widehat{r r}_{t}
\end{gathered}
$$




$$
\begin{gathered}
\widehat{Y}_{t}=\frac{\eta \nu}{\eta-(1-\nu)} \widehat{h}_{t-1}-\frac{1-\nu}{\eta-(1-\nu)}\left(\widehat{X}_{t}+\widehat{c}_{t}^{\prime}\right) \\
\widehat{\pi}_{t}=\beta E_{t} \widehat{\pi}_{t+1}-\kappa \widehat{X}_{t} \\
\widehat{R}_{t}=\left(1-r_{R}\right)\left(\left(1+r_{\pi}\right) \widehat{\pi}_{t-1}+r_{Y} \widehat{Y}_{t-1}\right)+r_{R} \widehat{R}_{t-1}+\widehat{e}_{R, t}
\end{gathered}
$$

where $\iota \equiv(1-\beta) h / h^{\prime}, \kappa \equiv(1-\theta)(1-\beta \theta) / \theta, \gamma_{e} \equiv m \beta+(1-m) \gamma$ and $\widehat{r r}_{t} \equiv \widehat{R}_{t}-E_{t} \widehat{\pi}_{t+1}$ is the ex ante real rate. L1 is total output. L2 is the Euler equation for household consumption. L3 is the entrepreneurial flow of funds. L4 and L5 express the consumption/housing margin for entrepreneurs and households respectively. L6 is the borrowing constraint. The supply side includes the production function L7 (combined with labor market clearing) and the Phillips curve L8. Finally, L9 is the monetary policy rule.

F. The transmission mechanism: indexation and collateral effects. The basic model shows the key links between the interest rate channel, the house price channel, and the debt deflation channel. I now focus on one standard deviation (as estimated in the VAR) negative monetary shock; in the full model, I will look at other disturbances too and will estimate some of the structural parameters of the model. The parameters chosen here reflect the estimates and the calibration of the full model.

The time period is a quarter. The entrepreneurial "loan-to-value" ratio $m$ is set to 0.89 . The probability of not changing prices $\theta$ is set to 0.75 . The discount factors are $\beta=0.99$ and $\gamma=0.98$. I set the elasticity of output to real estate $\nu$ to 0.03 (with $j=0.1$, this yields a steady state value of $h$, the entrepreneurial asset share, of 20 percent). The household labor supply schedule is assumed to be virtually flat: $\eta=1.01$.

For the Taylor rule, I set $r_{Y}=0, r_{\pi}=0.27, r_{R}=0.73$. These are the parameters of an estimated policy rule for the VAR period, with the exception of $r_{Y}$, which is reset to zero. Imposing $r_{Y}=0$ amplifies the financial accelerator since the central bank does not intervene when output falls. However, it allows isolating the exogenous component of the reaction function from its endogenous component, while ensuring determinacy of the rational expectations equilibrium. 
The transmission mechanism is simple: consider a negative monetary shock. With sticky prices, monetary actions affect the real rate, and its increase works by discouraging current consumption and hence output. The effect is reinforced through the fall in house prices, which leads to lower borrowing and lower entrepreneurial housing investment. Debt deflation plays a role too: as obligations are not indexed, deflation raises the cost of debt service, further depressing entrepreneurial consumption and investment.

How big are these effects? Figure 2 provides a stylized answer for three economies subject to the same shock, showing the total loss in output following a one-standard deviation increase $(0.29$ percent on a quarterly basis) of the interest rate. ${ }^{12}$ The solid line illustrates the case when both collateral and debt deflation effects are shut off, so that only the interest rate channel works (see Appendix B for the technical details): output falls by 3.33 percent. Here, the output drop is mainly driven from intertemporal substitution in consumption. The dashed line plots the response of output when the collateral channel becomes operational: the decline in output is larger, and the total decline is 3.82 percent. Finally, in the starred line, both collateral and debt deflation channel are at work: output falls by 4.42 percent. ${ }^{13}$

\section{The full model: household and entrepreneurial debt}

The basic model assumes that all mortgaged real estate is used by firms. In reality, financial frictions apply to both firms and households. The previous section models entrepreneurial consumption, but lacks the descriptive realism emphasized, for example, in the quote from Tobin at the beginning of the paper. In addition, investment occurs in the form of real estate transfers between agents, but net investment is zero. Before taking the model to the data, I extend it along two dimensions. On the one hand, I add a constrained, impatient household sector, that ends up facing a binding borrowing constraint in equilibrium. On the other, I allow variable capital investment for the entrepreneurs. This allows a more realistic analysis of the impact of a various range of disturbances: in particular, I add inflation, technology and taste shocks. As before, a central bank and retailers complete the model.

The problems of patient households, retailers and central bank are unchanged. I consider therefore the slightly modified entrepreneurial problem and then move to impatient households. 
A. Entrepreneurs. Entrepreneurs produce the intermediate good according to:

$$
Y_{t}=A_{t} K_{t-1}^{\mu} h_{t-1}^{\nu} L_{t}^{\prime \alpha(1-\mu-\nu)} L_{t}^{\prime \prime(1-\alpha)(1-\mu-\nu)}
$$

where $A_{t}$ is random. $L^{\prime}$ and $L^{\prime \prime}$ are the patient and impatient household labor ( $\alpha$ measures the relative size of each group) and $K$ is capital (that depreciates at rate $\delta$ ) created at the end of each period. For both housing and variable capital, I consider the possibility of adjustment costs: capital installation entails a $\operatorname{cost} \xi_{K, t}=\psi\left(I_{t} / K_{t-1}-\delta\right)^{2} K_{t-1} /(2 \delta)$, where $I_{t}=K_{t}-(1-\delta) K_{t-1}$. For housing, changing the stock entails a cost $\xi_{e, t}=\phi_{e}\left(\Delta h_{t} / h_{t-1}\right)^{2} q_{t} h_{t-1} / 2$, which is symmetric for each agent: such a cost might proxy for transaction costs, conversion costs of residential housing into commercial housing and vice versa, and so on. The remainder of the problem is unchanged: entrepreneurs maximize $E_{0} \sum_{t=0}^{\infty} \gamma^{t} \log c_{t}$, where $\gamma<\beta$, subject to technology (14) and borrowing constraint (10) as well as the flow of funds constraint:

$$
Y_{t} / X_{t}+b_{t}=c_{t}+q_{t} \Delta h_{t}+R_{t-1} b_{t-1} / \pi_{t}+w_{t}^{\prime} L_{t}^{\prime}+w_{t}^{\prime \prime} L_{t}^{\prime \prime}+I_{t}+\xi_{e, t}+\xi_{K, t} .
$$

The first order conditions for this problem are fairly standard and are reported in Appendix A.

B. Impatient households. Impatient households discount the future more heavily than the patient ones. They choose consumption $c_{t}^{\prime \prime}$, housing $h_{t}^{\prime \prime}$, labor $L_{t}^{\prime \prime}$ (and money $M_{t}^{\prime \prime} / P_{t}$ ) to maximize

$$
E_{0} \sum_{t=0}^{\infty}\left(\beta^{\prime \prime}\right)^{t}\left(\ln c_{t}^{\prime \prime}+j_{t} \ln h_{t}^{\prime \prime}-\left(L_{t}^{\prime \prime}\right)^{\eta} / \eta+\chi \ln M_{t}^{\prime \prime} / P_{t}\right)
$$

where $\beta^{\prime \prime}<\beta$. Like for entrepreneurs, this guarantees an equilibrium in which impatient households will hit the borrowing constraint. Here, the subscript under $j_{t}$ allows for random disturbances to the marginal utility of housing, and, given that it directly affects housing demand, offers a parsimonious way to assess the macro effects of an exogenous disturbance on house prices. ${ }^{14}$ The flow of funds and the borrowing limit are

$$
\begin{gathered}
c_{t}^{\prime \prime}+q_{t} \Delta h_{t}^{\prime \prime}+R_{t-1} b_{t-1}^{\prime \prime} / \pi_{t}=b_{t}^{\prime \prime}+w_{t}^{\prime \prime} L_{t}^{\prime \prime}+T_{t}^{\prime \prime}-\Delta M_{t}^{\prime \prime} / P_{t}-\xi_{h, t} \\
b_{t}^{\prime \prime} \leq m^{\prime \prime} E_{t}\left(q_{t+1} h_{t}^{\prime \prime} \pi_{t+1} / R_{t}\right)
\end{gathered}
$$

where $\xi_{h, t}=\phi_{h}\left(\Delta h_{t}^{\prime \prime} / h_{t-1}^{\prime \prime}\right)^{2} q_{t} h_{t-1}^{\prime \prime} / 2$ denotes the housing adjustment cost (an analogous term also appears in the budget constraint of the patient households). The borrowing constraint is consistent with 
standard lending criteria used in the mortgage market, which limit the amount lent to a fraction of the value of the asset. One can interpret the case $m^{\prime \prime}=0$ as the limit situation when housing is not collateralizable at all, so that households are excluded from financial markets.

Like for the entrepreneurs, the equations for consumption and housing choice (shown in Appendix A) hold with the addition of the multiplier associated to the borrowing restriction. ${ }^{15}$

C. The linearized model. The equations describing the steady state and the linearized model are isomorphic to those of the basic model and are in Appendix A. Before moving to the estimation strategy, I present two direct implications of the main model features which can replicate key dynamic correlations in the data: the collateral effect allows pinning down the elasticity of consumption to a housing preference shock; the nominal debt effect allows matching the delayed response of output to an inflation shock.

\section{Collateral effects and effects on consumption of a house price shock. Several commentators} have expressed the consideration that rising house prices have kept consumption growth high throughout the 1990's. Case, Quigley and Shiller (2003) find long-run elasticities of consumption to house prices around 0.06 for a panel of US states. Morris Davis and Michael Palumbo (2001) estimate a long-run elasticity of consumption to housing wealth of 0.08 . These positive elasticities are hard to reconcile with the traditional life-cycle model. Think about the simplest case, an exogenous increase in house prices. If the gains were equally distributed across all population, if all agents had the same propensity to consume and if all agents were to spend these gains on housing, total wealth less housing wealth would remain unchanged, and so would the demand for non-housing consumption. However, if liquidity constrained households value current consumption a lot, they may be able to increase their borrowing and consumption more than proportionally when house prices rise, so that increases in house prices might have positive effects on aggregate demand.

The above mechanism is at work in the paper, and it is straightforward to demonstrate its ability to produce an empirically plausible response of consumption to house price shocks. Figure 3 displays the impulse response of consumption to a persistent house price increase, generated from a shock to the marginal rate of substitution $j$ between housing and consumption for all households. Such an experiment 
offers a parsimonious way to model any kind of disturbance that shifts housing demand, such as temporary tax advantages to housing investment or a sudden increase in demand fuelled by optimistic consumer expectations. The parameters are those calibrated and estimated using the method described in Section IV, except that here I compute responses for several values of the loan-to-values $m$ and $m^{\prime \prime}$, and compare them with the impulse response from a house price shock in a VAR.

The VAR is estimated from $1974 Q 1$ to $2003 Q 2$ on quarterly data for the federal funds rate, log real house prices, log real personal consumption expenditures, log real GDP, log change in the GDP deflator, in that order. ${ }^{16}$ The figure illustrates an important point: the greater the importance of collateral effects (higher $m$ and $m^{\prime \prime}$ ), the closer the simulated elasticity of consumption to a house price shock. A wage share of the constrained sector $(1-\alpha)$ of 36 percent, loan-to-value ratios of 89 percent for entrepreneurial loans and 55 percent for residential loans can generate responses of consumption (and income, as will be shown below) to a house price shock that are not only qualitatively but also quantitatively in line with the VAR estimates. In particular, the impact elasticity of consumption to a persistent 1 percent increase in housing prices is around 0.2 : this is slightly larger than reduced-form estimates found in the studies above; however, both in the model and in the VAR consumption falls below the baseline during the transition, hence the medium-run elasticities are somewhat smaller. Instead, the model without collateral effects $\left(m, m^{\prime \prime} \rightarrow 0\right)$ predicts a negative response of consumption to house prices - mainly driven by a substitution effect between housing and consumption -, which is clearly at odds with the data.

While I will conduct more formal estimation and testing below, this pictures highlights the reason behind the success of the model in tracking down the empirical positive elasticity of spending to house prices. To better understand the result, it is useful to reinterpret the borrowers' asset demand as determining consumption given asset prices and payoffs, rather than determining today's asset prices in terms of consumption and payoffs. For entrepreneurs, for instance, the linearized optimality condition between housing and consumption can be written (neglecting adjustment costs) as

$$
\widehat{c}_{t}=E_{t} \widehat{c}_{t+1}+\frac{1}{1-m \beta}\left(\widehat{q}_{t}-\gamma_{e} E_{t} \widehat{q}_{t+1}-\left(1-\gamma_{e}\right) E_{t} \widehat{S}_{t+1}\right)+\frac{m \beta}{1-m \beta} \widehat{r r}_{t}
$$

where $\gamma_{e} \equiv m \beta+(1-m) \gamma$ and $E_{t} \widehat{S}_{t+1}$ is the expected marginal product of housing. This equation clearly 
shows how, keeping constant expected consumption, expected returns on housing and real interest rates, the multiplier effect on consumption of given changes in $q_{t}$ can be rather large, and is strongly increasing with $m$, the loan-to-value ratio. Instead, as shown by equation L5, for lenders the effects of $q_{t}$ on $c_{t}$ are simply one-for-one, and therefore much smaller in magnitude.

E. Debt deflation and the stabilizing effects of an inflation shock. Starting from the steady state, I assume a one percent, persistent inflation surprise. ${ }^{17}$ It is informative to contrast the response of output with nominal debt to the model with indexed debt. Figure 4 displays the results of the simulation.

With nominal debt (solid line), the rise in prices reduces the desired supply of goods at a given price level; at the same time, it transfers wealth from the lenders towards the borrowers, who, ceteris paribus, have a higher propensity to consume. Initially, the two effects go in opposite directions, and output falls by a small amount. Later, the first effect dominates, and the output drop is larger: overall, output displays a hump-shaped pattern and a slow return to its initial steady state.

This contrasts with the responses that would occur in a model without debt deflation effects (dashed line): with indexed debt, the drop in output is immediate and stronger in magnitude, because the beneficial effects of inflation are absent. Hence, the assumption of nominal debt helps capturing not only qualitatively but also quantitatively the hump-shaped and persistent response of output to inflation found in the VAR.

Interestingly, the negative correlation between inflation and output induced by an inflation shock acts as a built-in stabilizer for the economy. Debt deflation thus adds a new twist to the theories of financial accelerator mentioned in the introduction: while it amplifies demand-type disturbances, it can stabilize those that generate a trade-off between output and inflation. I will return to this issue in Section VI.

\section{Econometric methodology}

I now discuss the methodology for evaluating the model. I partition the model parameters in three groups. 
A. Calibration. The first group includes the discount factors: $\beta, \beta^{\prime \prime}, \gamma$; the housing weight $j$; the technology parameters: $\mu, \nu, \delta, \psi, \phi_{e}, \phi_{h}$; the markup $X$; the labor disutility $\eta$; the degree of price rigidity $\theta$. I calibrate these parameters on the basis of the data sample means and other studies because they contain relatively more information on the first moments of the data.

For the standard parameters, I choose values which are within the range considered in the monetary/real business cycle literature. Thus, $\beta, \delta, \mu, X, \theta$ and $\eta$ equal $0.99,0.03,0.3,1.05,0.75$ and 1.01 respectively. ${ }^{18}$

Next, I set $\gamma$ and $\beta^{\prime \prime}$. I match the reciprocal of $\gamma$, which proxies for the firm's internal rate of return. I assume this is twice as big as the equilibrium real rate, and set $\gamma=0.98$. I then pick a value for $\beta^{\prime \prime}$ : Emily Lawrance (1991) estimates discount factors for poor households (which are more likely to be debtors) between 0.95 and 0.98 at quarterly frequency, depending on the specification. Carroll and Andrew Samwick (1997) calculate an empirical distribution of discount factors for all agents using information on the elasticity of assets with respect to uncertainty: the two standard deviation bands range in the interval $(0.91,0.99)$. Samwick (1998) uses wealth holdings at different ages to infer the underlying distribution of discount factors: for about 70 percent of the households, he finds mean discount factors of about 0.99 ; for about 25 percent of households, he estimates discount factors below 0.95 . With $\beta$ set at 0.99 , I choose $\beta^{\prime \prime}=0.95$, in the ballpark of these estimates.

I set $\nu$, the elasticity of output to entrepreneurial real estate, to 0.03 . This number implies a plausible 62 percent for the steady state value of commercial real estate over annual output. The parameter $j$ mainly controls the stock of residential housing over annual output (see Appendix A): $j=0.1$ fixes this ratio at 140 percent, in line with data from the Flow of Funds accounts (see e.g. Table B.100, row 4).

I then pick values for the adjustment cost parameters. Preliminary attempts to estimate these parameters (using the methods described in Section IV.C) led to estimates of the capital adjustment cost $\psi$ around 2 and pushed the housing adjustment cost parameters $\phi_{e}$ and $\phi_{h}$ towards zero. These results suggest that the data appear to favor a version of the model in which variable capital moves more slowly than housing in response to disturbances. Although this finding is not in contraddiction for the cyclical properties of the actual data, ${ }^{19}$ it is likely that the solution algorithm has difficulty in 
estimating these parameters without data on the types of investment spending. At the same time, one has to consider that, ceteris paribus, the fixity of the housing stock in the aggregate works by itself as an adjustment cost on housing investment: given that the total supply of structures is fixed, additional housing investment in any given period drives up the price of the existing stock, so that, from each agent's point of view, every unit of new investment is more costly at the margin. In what follows, therefore, I estimate the model by calibrating $\psi=2$ and $\phi_{e}=\phi_{h}=0 .{ }^{20}$ The former implies an elasticity of $1 / 2$ of investment to the capital shadow price, following Robert King and Alex Wolman (1996): this value is well within the range of estimates reported in the literature (see Robert Chirinko (1993)). Table 1 summarizes the parameters.

B. Policy rule. The second group includes the parameters which can be recovered from the estimates of the Taylor rule. For the period 1974Q1-2003Q2, an OLS regression of the Fed Funds rate on its own lag, past inflation and detrended output yields $r_{R}=0.73, r_{Y}=0.13, r_{\pi}=0.27 .^{21}$

C. Estimation. The third group includes the autocorrelation and the standard deviation of each shock $\left(\rho_{A}, \rho_{j}, \rho_{u}, \sigma_{A}, \sigma_{j}, \sigma_{u}\right)$ the loan-to-value ratios $\left(m, m^{\prime \prime}\right)$, and the wage income share of the patient households, measured by $\alpha$. I estimate these parameters by minimizing a measure of the distance between the empirical impulse responses (Section I), and the model responses, which were obtained from the reduced form of the model by ordering and orthogonalizing the shocks as in the VAR.

As is well known (see e.g. Ireland, 2004a), the number of data series in the VAR representation cannot exceed the number of structural disturbances in the model. With four disturbances (monetary, inflation, taste, productivity), I select $(R, \pi, q, Y)$ as the variables of interest. Denote with $\boldsymbol{\Psi}(\boldsymbol{\zeta})$ the vector collecting the model orthogonalized impulse responses, obtained from the reduced form of the model by ordering and orthogonalizing the impulse responses as in the VAR. Let $\widehat{\boldsymbol{\Psi}}$ be the $n \times 1$ vector of empirical estimates of the VAR impulse responses. ${ }^{22}$ I include the first 20 elements of each impulse response function, excluding those that are zero by the recursiveness assumption. The estimate of $\boldsymbol{\zeta}$, a vector of parameters, solves

$$
\min _{\zeta}(\boldsymbol{\Psi}(\boldsymbol{\zeta})-\widehat{\Psi})^{\prime} \mathbf{\Phi}(\boldsymbol{\Psi}(\boldsymbol{\zeta})-\widehat{\Psi})
$$


where $\boldsymbol{\Phi}$ is a $n \times n$ weighting matrix. Under the null hypothesis that the VAR model is true and that the model fits the data, the optimal weighting matrix $\boldsymbol{\Phi}$ would equal $\boldsymbol{\Phi}=\boldsymbol{\Upsilon}^{-1}$, the inverse of the matrix with the sample variances of the VAR impulse responses on the main diagonal. Given that the crosscorrelations between $q$ and $Y$ are likely to be relatively more informative for $m, m^{\prime \prime}$ and $\alpha$, I specify $\boldsymbol{\Phi}=\boldsymbol{\Omega} \boldsymbol{\Upsilon}^{-1}$, where $\boldsymbol{\Omega}$ is a $n \times n$ diagonal matrix of weights that gives a weight four times larger to all the dynamic cross-correlations involving $q$ and $Y$. This way, I still get consistent (yet inefficient) estimates of all the parameters, but at the same time I fit the moments of highest interest. ${ }^{23}$ The results were however robust to the choice of $\Omega$.

Table 2 summarizes the estimates of the parameters in $\boldsymbol{\zeta}$. The results strongly support the presence of borrowing constrained households: their wage share $(1-\alpha)$ is around 36 percent and is precisely estimated: ${ }^{24}$ interestingly, this number is within the range of the various studies that, since Campbell and Mankiw (1989), have estimated from consumption Euler equations the fraction of rule-ofthumb/constrained agents in an economy. At the same time, they also support strong effects on demand from changes in asset values, as shown by the high values of $m$ and $m^{\prime \prime}$. The former is 89 percent, whereas the latter is 55 percent. Hence, the estimates suggest that entrepreneurial real estate is more easily collateralizable than household real estate. A joint test of the hypothesis that collateral constraints are unimportant - that the $m$ and $m^{\prime \prime}$ are equal to zero - is overwhelmingly rejected. High values of $m$ and $m^{\prime \prime}$ are in fact needed to generate strong and persistent effects on aggregate demand from given changes in asset values, something that a model without these effects cannot replicate.

Finally, the estimate of the autocorrelation in the technology shock is low $\left(\rho_{A}=0.03\right)$ and less precisely estimated: one explanation might be the detrending method used in the VAR, which takes away the low-frequency component of GDP. Instead, the autocorrelations in the preference and in the inflation shock are both precisely estimated and highlight moderate persistence in the shock processes $\left(\rho_{j}=0.85, \rho_{u}=0.59\right)$. Interestingly, such autocorrelations are lower than what found in estimates of standard monetary business cycle models: one possibility might be that the endogenous propagation mechanisms that are at work in the model require less persistent shocks to fit the second moment properties of the data. 
While the estimates of $\alpha, m$ and $m^{\prime \prime}$ are all statistically significant, ${ }^{25} \mathrm{I}$ reject the null hypothesis of equality between the model and the data. Perhaps the simplest explanation for this finding is that the model lacks features such as expectational delays, inertial adjustment of prices or habit persistence that elsewhere authors have shown can help replicating the delayed responses of macroeconomic variables to various shocks (see e.g. Julio Rotemberg and Michael Woodford, 1997, Galí and Gertler, 1999, Fuhrer, 2000).

\section{More on the model dynamics}

Figure 5 shows the model impulse responses and compares them with the VAR impulse responses. This way, I can assess the key properties of the model and its consistency with empirical evidence. ${ }^{26}$

The top row shows a monetary tightening. The drop in output is immediate in the model, while is delayed in the data, although the total output sacrifice is in line with the VAR estimate. As in the basic model, money shocks have heterogeneous effects: debtors bear most of the brunt of the monetary contraction, while consumption of lenders is mildly affected, and can be shown to rise above the baseline in the transition to the steady state. In turn, the real rate, which prices lenders' behavior, falls below the baseline in the transition. Real house prices initially fall below the baseline deepening the recession and then overshoot above the baseline, preceding the economy's recovery.

The previous section has already shown how nominal debt is successful in capturing the sluggish response of output to an inflation shock. The second row of Figure 5 shows that the model does very well at capturing the positive response of the interest rate and the negative response of house prices to an inflation surprise.

For the preference shock, the third row of Figure 5 shows that the model does well in capturing also the positive elasticities of demand and inflation to an house price shock. Figure 3 has already shown how a model without collateral effects predicts a small, even negative, response of aggregate demand to a house price shock. ${ }^{27}$

The last row of Figure 5 shows the responses to a transitory productivity rise. Here it is harder to compare the responses of the model with the data, especially because it is harder to consider the VAR 
disturbance a pure productivity shock: for instance, a government spending shock could be observationally equivalent. In the model, output and asset prices peak only with a delay following the improvement in productivity.

In simulations not reported here, I find that the model predicts a standard deviation for entrepreneurial housing investment that is twice that of variable capital investment: this number is slightly bigger but roughly in line with the data (see footnote 19). Not shown in figure, I find that in response to, say, a negative monetary shock (positive preference shock), $h$ falls (rises) on impact by 4 percent (3 percent). Given that the elasticity of output to real estate is very small (0.03), this shows that changes in housing ownership per se are not crucial to the trasmission mechanism: rather, it is the general equilibrium effects working through the demand for all factors of production that affect the aggregate outcomes. ${ }^{28}$

\section{Systematic monetary policy and policy frontiers}

Shocks which generate a negative correlation between output and inflation force the central bank to face a trade-off between the variability of output and that of inflation. A natural question is: how do different monetary policy rules and contractual arrangements affect the cyclical properties of output and inflation? This section gives an answer, based on the assumption that output and inflation volatility are the only two goals of monetary policy. I consider two questions: (1) should interest rates respond to house prices? (2) how do different financing arrangements (nominal versus indexed debt) affect the volatility of the economy?

A. Should central banks respond to house prices? I compute the inflation-output volatility frontiers for alternative parameterizations of the interest rate rule as in Andrew Levin, Volker Wieland and John Williams (1999), subject to a constraint on interest rate volatility. ${ }^{29}$ The class of rules I consider is

$$
\widehat{R}_{t}=0.73 \widehat{R}_{t-1}+0.27\left(r_{q} \widehat{q}_{t}+\left(1+r_{\pi}\right) \widehat{\pi}_{t-1}+r_{Y} \widehat{Y}_{t-1}\right)
$$

In other words, I assume that the central bank can respond to current asset price movements: this way, I shift the bias in favor of finding a non-zero coefficient on asset prices in the reaction function. 
I compute two efficient frontiers. In the first one, I fix $r_{q}=0$; in the second, I allow $R_{t}$ to respond to $q_{t}$. This way, I investigate the extent to which responding to asset prices can yield lower output and inflation volatility. Altogether, responding to asset prices does not yield significant gains in terms of output and inflation stabilization. As shown by Figure 6, the frontier obtained by responding to asset prices shifts inwards only marginally: keeping inflation standard deviation constant, the decrease in the standard deviation of output is a rather small number, about 0.7 percent of its baseline value. The optimal $r_{q}$ is positive and slightly increasing in the weight given to output stabilization in the loss function, ranging between 0.1 and 0.15 . However, such a weight is small compared to the optimal responses to output and inflation. $^{30}$

The unimportance of responding to asset prices is reminiscent of the findings of Bernanke and Gertler (2001) and Gilchrist and John Leahy (2002). They look at whether central banks should respond to stock prices in a version of the Bernanke, Gertler and Gilchrist (1999) model which allows for fundamental and non-fundamental asset price changes. They find no case for responding to stock prices, although they do not calculate a complete efficient frontier for different policy rule specifications. In their setup, the signal-to-noise ratio of asset prices is too low for asset prices to be informative for the central bank. Here, asset prices matter in that they transmit and amplify a range of disturbances to the real sector. Despite this, if the central bank wants to minimize output and inflation fluctuations, little is gained by responding to asset prices, even if their current movements are in the policymaker information set.

B. Does debt indexation reduce economic volatility? Earlier, I have shown how the model can deliver a smaller response of output to monetary shocks when debt contracts can be indexed to the price level, but that indexed debt does not dampen output responses to inflation or technology shocks. Consider a positive inflation surprise: this shock causes a stronger output decline in the indexed debt model, since, while demand drops in both cases, borrowers do not get the benefit of lower real repayments as before. Hence, indexed debt stabilizes only the type of disturbances that monetary policy can offset. In the presence of "supply" shocks, the Taylor curve in an economy with indexed debt lies above that for an economy with nominal debt (Figure 7). This result is somewhat surprising, and goes counter 
the widely held wisdom that high levels of household and firm debt may threaten economic stability. However, it is a natural consequence of two causes: first, the shocks that matter for the trade-off are only those that move the target variables in opposite direction; second, the accelerator of demand shocks gives more leverage to the central bank, and implies that smaller interest rate changes are needed to stabilize the economy for given demand disturbance.

It is interesting to consider how the results change when the trade-off involves inflation and output gap, defined as the shortfall of output from its equilibrium level under flexible prices (as proxied by

$X_{t}$, the time-varying markup). The main difference with the baseline case concerns technology shocks. Consider, say, a favorable technology shock: for a given drop in prices, output rises less with nominal debt than with indexed debt because of the negative deflation effect; however, output gap rises more with nominal debt than with indexed debt because, while in both cases downward price stickiness prevents aggregate demand from rising enough to meet the higher supply, debt-deflation implies that demand rises even less if debt is not indexed. Hence the gap is bigger under nominal debt, and, if the technology shocks were the only source of supply-side fluctuations, the trade-off would be worsened under nominal debt. Quantitatively, whether nominal debt is better than indexed debt depends on the relative standard deviation of inflation versus technology shocks and on the policymaker's preferences. ${ }^{31}$ Figure 8 shows the two Taylor curves in output gap/inflation standard deviation space: if the weight on inflation stabilization is large, the central bank can offset technology shocks better than inflation shocks, and nominal debt dominates indexed debt. If the weight on output stabilization is large, the reverse is true, and indexed debt yields a better trade-off.

\section{Concluding remarks}

My model adds two important dimensions to the literature on financial frictions and the macroeconomy: nominal debt contracts, and collateral constraints tied to housing values on both the firm and the household side. It then takes them to the data. The improvements afforded by these features arise in two important and distinct ways. First, collateral effects allow the model to match the positive response of real spending to a house price shock. Second, nominal debt can accurately replicate the sluggish 
dynamics of spending to an inflation surprise. ${ }^{32}$

Given that the model is quite successful in matching some key properties of the data, one can conduct quantitative policy analysis. In particular, I show how the fact that debt-deflation amplifies demand shocks, but stabilizes supply shocks yields an improved output-inflation variance trade-off for the central bank. I also show that responding to asset prices does not yield significant welfare gains.

One limitation of the model is that it rules out buffer-stock behavior: key to this result is that aggregate uncertainty is small relative to the degree of impatience of borrowers. In Appendix C, ${ }^{33}$ I investigate this issue in a partial equilibrium model of consumption and housing investment with borrowing constraints which features an amount of uncertainty which is sufficient to replicate the aggregate output volatility in the data. The non-linear solution shows how such uncertainty is small enough to generate non-negligible buffer-stock behavior. In particular, agents borrow up to the limit in all states unless the standard deviation of the underlying aggregate shock rises to about four times more than what is needed to replicate the actual data. While these results are suggestive, ideally one would like to embed this extension in a full-blown general equilibrium model that endogenizes quantities as well prices, and that introduces idiosyncratic risk in addition to aggregate risk. Assessing this is an important task for future research. ${ }^{34}$ 


\section{Appendix A: Steady state and Log-Linearizations}

Steady state of the basic model. Assuming zero inflation (so that $R=1 / \beta$ ), the steady state will be described by:

$$
\begin{aligned}
\frac{h}{H} & =\frac{\gamma \nu(1-\beta)}{\gamma \nu(1-\beta)+j\left((X-\nu)\left(1-\gamma_{e}\right)+\gamma \nu(1-\beta) m\right)} \\
\frac{q h}{Y} & =\frac{\gamma \nu}{1-\gamma_{e}} \frac{1}{X} \\
\frac{b}{Y} & =\frac{\beta m \gamma \nu}{1-\gamma_{e}} \frac{1}{X} \\
\frac{c}{Y} & =\frac{\nu}{X}-(1-\beta) m \frac{q h}{Y}=\nu \frac{(1-\gamma)(1-\beta m)}{1-\gamma_{e}} \frac{1}{X} \\
\frac{c^{\prime}}{Y} & =\frac{X-\nu}{X}+(1-\beta) m \frac{q h}{Y}=\left(X-\nu+\frac{\gamma \nu(1-\beta) m}{1-\gamma_{e}}\right) \frac{1}{X}
\end{aligned}
$$

where $\gamma_{e} \equiv(1-m) \gamma+m \beta$ is the average discount factor for the returns to entrepreneurial real estate investment.

The impatient household problem in the extended model. Denoting with $\lambda^{\prime \prime}$ the multiplier on the borrowing constraint, the first order conditions are

$$
\begin{aligned}
\frac{1}{c_{t}^{\prime \prime}} & =E_{t}\left(\frac{\beta^{\prime \prime} R_{t}}{\pi_{t+1} c_{t+1}^{\prime \prime}}\right)+\lambda_{t}^{\prime \prime} R_{t} \\
\frac{q_{t}}{c_{t}^{\prime \prime}}\left(1+\phi_{h} \frac{\Delta h_{t}^{\prime \prime}}{h_{t-1}^{\prime \prime}}\right) & =\frac{j_{t}}{h_{t}^{\prime \prime}}+E_{t}\left(\frac{\beta^{\prime \prime} q_{t+1}}{c_{t+1}^{\prime \prime}}\left(1+\phi_{h} \frac{\Delta h_{t+1}^{\prime \prime}}{h_{t}^{\prime \prime}}\right)+\lambda_{t}^{\prime \prime} m^{\prime \prime} q_{t+1} \pi_{t+1}\right) \\
w_{t}^{\prime \prime} / c_{t}^{\prime \prime} & =\left(L_{t}^{\prime \prime}\right)^{\eta-1} .
\end{aligned}
$$

The entrepreneurial problem in the extended model. The first order conditions are

$$
\begin{aligned}
v_{t} & =\frac{1}{c_{t}}\left(\frac{\psi}{\delta}\left(\frac{I_{t}}{K_{t-1}}-\delta\right) \frac{I_{t}}{K_{t-1}}-\frac{\psi}{2 \delta}\left(\frac{I_{t}}{K_{t-1}}-\delta\right)^{2}\right)+\gamma E_{t}\left(\frac{\mu Y_{t+1}}{c_{t+1} X_{t+1} K_{t}}+v_{t+1}(1-\delta)\right) \\
w_{t}^{\prime} & =\alpha(1-\mu-\nu) Y_{t} /\left(X_{t} L_{t}^{\prime}\right) \\
w_{t}^{\prime \prime} & =(1-\alpha)(1-\mu-\nu) Y_{t} /\left(X_{t} L_{t}^{\prime \prime}\right)
\end{aligned}
$$

where $v_{t}=\frac{1}{c_{t}}\left(1+\frac{\psi}{\delta}\left(\frac{I_{t}}{K_{t-1}}-\delta\right)\right)$, together with $(7)$ and (8), the latter modified to include the adjustment cost terms.

The first equation says that the shadow price of capital $v_{t}$ must equal the capital's marginal product next period plus the capital contribution to lower installation costs plus the shadow value of capital in 
the next period. In addition, there are two labor demand schedules.

Steady state of the extended model. The values of commercial real estate and commercial debt over output $(q h / Y$ and $b / Y)$ are unchanged from the basic model. Let $s^{\prime} \equiv(\alpha(1-\mu-\nu)+X-1) / X$, $s^{\prime \prime} \equiv(1-\alpha)(1-\mu-\nu) / X$ be the income shares of patient and impatient households. The real estate shares for each household are

$$
\begin{aligned}
\frac{q h^{\prime}}{Y} & =\frac{j}{1-\beta} s^{\prime}+\frac{j m \gamma \nu}{1-\gamma_{e}} \frac{1}{X}+\frac{j}{1-\beta^{\prime \prime}-m^{\prime \prime}\left(\beta-\beta^{\prime \prime}-j(1-\beta)\right)} m^{\prime \prime} s^{\prime \prime} \\
\frac{q h^{\prime \prime}}{Y} & =\frac{j}{1-\beta^{\prime \prime}-m^{\prime \prime}\left(\beta-\beta^{\prime \prime}-j(1-\beta)\right)} s^{\prime \prime} .
\end{aligned}
$$

The debt to output and the consumption to output ratio for the impatient household are

$$
\begin{aligned}
\frac{b^{\prime \prime}}{Y} & =\frac{j \beta m^{\prime \prime}}{1-\beta^{\prime \prime}-m^{\prime \prime}\left(\beta-\beta^{\prime \prime}\right)+j m^{\prime \prime}(1-\beta)} s^{\prime \prime} \\
\frac{c^{\prime \prime}}{Y} & =\frac{1-\beta^{\prime \prime}-m^{\prime \prime}\left(\beta-\beta^{\prime \prime}\right)}{1-\beta^{\prime \prime}-m^{\prime \prime}\left(\beta-\beta^{\prime \prime}\right)+j m^{\prime \prime}(1-\beta)} s^{\prime \prime} .
\end{aligned}
$$

The consumption to output ratio for the entrepreneurs is

$$
\frac{c}{Y}=\left(\mu+\nu-\frac{\delta \gamma \mu}{1-\gamma(1-\delta)}-\frac{(1-\beta) m \gamma \nu}{1-\gamma_{e}}\right) \frac{1}{X}
$$

The complete log-linearized model. To save on notation, I drop the expectation operator before variables dated $t+1$, which must be intended in expected value conditional on the information available at time $t$. The model can be expressed in six blocks of equations:

1. aggregate demand

$$
\begin{aligned}
\widehat{Y}_{t} & =\frac{c}{Y} \widehat{c}_{t}+\frac{c^{\prime}}{Y} \widehat{c}_{t}^{\prime}+\frac{c^{\prime \prime}}{Y} \widehat{c}_{t}^{\prime \prime}+\frac{I}{Y} \widehat{I}_{t} \\
\widehat{c}_{t}^{\prime} & =\widehat{c}_{t+1}^{\prime}-\widehat{r r}_{t} \\
\widehat{I}_{t}-\widehat{K}_{t-1} & =\gamma\left(\widehat{I}_{t+1}-\widehat{K}_{t}\right)+\frac{1-\gamma(1-\delta)}{\psi}\left(\widehat{Y}_{t+1}-\widehat{X}_{t+1}-\widehat{K}_{t}\right)+\frac{1}{\psi}\left(\widehat{c}_{t}-\widehat{c}_{t+1}\right)
\end{aligned}
$$


2. housing / consumption margin

$$
\begin{aligned}
& \widehat{q}_{t}=\gamma_{e} \widehat{q}_{t+1}+\left(1-\gamma_{e}\right)\left(\widehat{Y}_{t+1}-\widehat{X}_{t+1}-\widehat{h}_{t}\right)-m \beta \widehat{r r}_{t}-(1-m \beta) \Delta \widehat{c}_{t+1}-\phi_{e}\left(\Delta \widehat{h}_{t}-\gamma \Delta \widehat{h}_{t+1}\right) \text { (A4) } \\
& \widehat{q}_{t}=\gamma_{h} \widehat{q}_{t+1}+\left(1-\gamma_{h}\right)\left(\widehat{j}_{t}-\widehat{h}_{t}^{\prime \prime}\right)-m^{\prime \prime} \beta \widehat{r}_{t}+\left(1-m^{\prime \prime} \beta\right)\left(\widehat{c}_{t}^{\prime \prime}-\omega \widehat{c}_{t+1}^{\prime \prime}\right)-\phi_{h}\left(\Delta \widehat{h}_{t}^{\prime \prime}-\beta^{\prime \prime} \Delta \widehat{h}_{t+1}^{\prime \prime}\right)(\mathrm{A} 5) \\
& \left.\widehat{q}_{t}=\beta \widehat{q}_{t+1}+(1-\beta) \widehat{j}_{t}+\iota \widehat{h}_{t}+\iota^{\prime \prime} \widehat{h}_{t}^{\prime \prime}+\widehat{c}_{t}^{\prime}-\beta \widehat{c}_{t+1}^{\prime}+\frac{\phi_{h}}{h^{\prime}}\left(h \Delta \widehat{h}_{t}+h^{\prime \prime} \Delta \widehat{h}_{t}^{\prime \prime}-\beta h \Delta \widehat{h}_{t+1}-\beta h^{\prime \prime} \Delta \widehat{h}_{t+(\mathrm{f})}^{\prime \prime}\right) 6\right)
\end{aligned}
$$

3. borrowing constraints

$$
\begin{aligned}
\widehat{b}_{t} & =\widehat{q}_{t+1}+\widehat{h}_{t}-\widehat{r r}_{t} \\
\widehat{b}_{t}^{\prime \prime} & =\widehat{q}_{t+1}+\widehat{h}_{t}^{\prime \prime}-\widehat{r r}_{t}
\end{aligned}
$$

4. aggregate supply

$$
\begin{aligned}
\widehat{Y}_{t} & =\frac{\eta}{\eta-(1-\nu-\mu)}\left(\widehat{A}_{t}+\nu \widehat{h}_{t-1}+\mu \widehat{K}_{t-1}\right)-\frac{1-\nu-\mu}{\eta-(1-\nu-\mu)}\left(\widehat{X}_{t}+\alpha \widehat{c}_{t}^{\prime}+(1-\alpha) \widehat{c}_{t}^{\prime \prime}\right) \\
\widehat{\pi}_{t} & =\beta \widehat{\pi}_{t+1}-\kappa \widehat{X}_{t}+\widehat{u}_{t}
\end{aligned}
$$

5. Flows of funds / Evolution of state variables

$$
\begin{aligned}
\widehat{K}_{t} & =\delta \widehat{I}_{t}+(1-\delta) \widehat{K}_{t-1} \\
\frac{b}{Y} \widehat{b}_{t} & =\frac{c}{Y} \widehat{c}_{t}+\frac{q h}{Y} \Delta \widehat{h}_{t}+\frac{I}{Y} \widehat{I}_{t}+\frac{R b}{Y}\left(\widehat{R}_{t-1}+\widehat{b}_{t-1}-\widehat{\pi}_{t}\right)-\left(1-s^{\prime}-s^{\prime \prime}\right)\left(\widehat{Y}_{t}-\widehat{X}_{t}\right) \\
\frac{b^{\prime \prime}}{Y} \widehat{b}_{t}^{\prime \prime} & =\frac{c^{\prime \prime}}{Y} \widehat{c}_{t}^{\prime \prime}+\frac{q h^{\prime \prime}}{Y} \Delta \widehat{h}_{t}^{\prime \prime}+\frac{R b^{\prime \prime}}{Y}\left(\widehat{b}_{t-1}^{\prime \prime}+\widehat{R}_{t-1}-\widehat{\pi}_{t}\right)-s^{\prime \prime}\left(\widehat{Y}_{t}-\widehat{X}_{t}\right)
\end{aligned}
$$

6. Monetary policy rule and shock processes

$$
\begin{aligned}
\widehat{R}_{t} & =\left(1-r_{R}\right)\left(1+r_{\pi}\right) \widehat{\pi}_{t-1}+r_{Y}\left(1-r_{R}\right) \widehat{Y}_{t-1}+r_{R} \widehat{R}_{t-1}+\widehat{e}_{R, t} \\
\widehat{j}_{t} & =\rho_{j} \widehat{j}_{t-1}+\widehat{e}_{j, t} \\
\widehat{u}_{t} & =\rho_{u} \widehat{u}_{t-1}+\widehat{e}_{u, t} \\
\widehat{A}_{t} & =\rho_{A} \widehat{A}_{t-1}+\widehat{e}_{A, t}
\end{aligned}
$$


where $\omega=\left(\beta^{\prime \prime}-m^{\prime \prime} \beta^{\prime \prime}\right) /\left(1-m^{\prime \prime} \beta\right), \iota=(1-\beta) h / h^{\prime}, \iota^{\prime \prime}=(1-\beta) h^{\prime \prime} / h^{\prime}, \gamma_{h} \equiv \beta^{\prime \prime}+m^{\prime \prime}\left(\beta-\beta^{\prime \prime}\right)$, and $\widehat{r r}_{t} \equiv \widehat{R}_{t}-E_{t} \widehat{\pi}_{t+1}$ is the ex ante real rate.

A1 is the goods market clearing. A2 is the patient household's first-order conditions for consumption. A3 is the investment schedule. The entrepreneurial optimality condition for consumption/housing is A4, the impatient households' is A5, and the patient households demand (incorporating market clearing) is A6 (the last brackets in each equation account for the adjustment cost). The borrowing constraint for firms is A7, for households is A8. A9 is the production function together with labor market clearing, A10 is the Phillips curve. A11 is the law of motion for capital. A12 and A13 describe the net worth dynamics of entrepreneurs and constrained households respectively. A14 is the monetary policy rule. The last equations specify the stochastic $\mathrm{AR}(1)$ processes for preferences, inflation and technology.

\section{Appendix B: Alternative modeling assumptions}

Indexed debt. If debt is indexed to the price level, the entrepreneur borrows $B_{t}$ and pays back the realized real value of his debt, that is $R_{t-1} \frac{P_{t}}{P_{t-1}} B_{t-1}$. In the basic model, the entrepreneurial flow of funds becomes

$$
Y_{t} / X_{t}+b_{t}=c_{t}+q_{t} \Delta h_{t}+R_{t-1} b_{t-1}+w_{t}^{\prime} L_{t}
$$

The entrepreneurial new Euler equation is

$$
1 / c_{t}=\gamma E_{t}\left(R_{t} / c_{t+1}\right)+\lambda_{t} R_{t}
$$

whereas Euler equation for the unconstrained households is

$$
1 / c_{t}^{\prime}=\beta E_{t}\left(R_{t} / c_{t+1}^{\prime}\right)
$$

so that now lenders' behavior prices nominal bonds.

No asset price channel. The borrowing limit is $B_{t}=P_{t} \bar{B} / R$, where $\bar{B} / R$ is a constant independent from the asset value. The first order conditions for consumption and housing choice become

$$
\begin{aligned}
\frac{1}{c_{t}} & =\gamma E_{t}\left(\frac{R_{t}}{\pi_{t+1} c_{t+1}}\right)+\lambda_{t} R \\
\frac{1}{c_{t}} q_{t} & =\gamma E_{t}\left(\frac{1}{c_{t+1}}\left(\nu \frac{Y_{t+1}}{X_{t+1} h_{t}}+q_{t+1}\right)\right) .
\end{aligned}
$$




\section{References}

[1] Aoki, Kosuke; Proudman James and Vlieghe Jan. "House prices, consumption, and monetary policy: a financial accelerator approach." Journal of Financial Intermediation, 2004, (13), pp. 41435.

[2] Bernanke, Ben S. "Permanent Income, Liquidity, and Expenditure on Automobiles: Evidence From Panel Data." Quarterly Journal of Economics, August 1984, 99(3), pp. 587-614.

[3] Bernanke, Ben S. and Gertler Mark, "Agency Costs, Net Worth and Business Fluctuations." American Economic Review, March 1989, 79(1), pp. 14-31.

[4] Bernanke Ben S.; Gertler Mark, and Gilchrist Simon. "The Financial Accelerator in a Quantitative Business Cycle Framework", in John B. Taylor and Michael Woodford, eds., Handbook of Macroeconomics, Vol. 1C. Amsterdam: North-Holland, 1999, pp. 1341-1393.

[5] Bernanke, Ben S. and Gertler Mark. "Should Central Banks Respond to Movements in Asset Prices?." American Economic Review, May 2001 (Papers and Proceedings), 91(2), pp. 253-257.

[6] Campbell, John Y. and Mankiw Gregory N. "Consumption, Income and Interest Rates: Reinterpreting the Time Series Evidence," in in Olivier J. Blanchard and Stanley Fisher, eds., NBER Macroeconomics Annual 1989, Cambridge MA: MIT Press, pp. 185-216.

[7] Carlstrom, Charles T. and Fuerst Timothy S. "Agency Costs, Net Worth and Business Fluctuations: A Computable General Equilibrium Analysis." American Economic Review, December 1997, 87(5), pp. 893-910.

[8] ___. "Monetary shocks, agency costs, and business cycles." Carnegie-Rochester Conference Series on Public Policy, 2001, 54, pp. 1-27.

[9] Carroll, Christopher D. and Dunn Wendy D. "Unemployment Expectations, Jumping (S,s) Triggers, and Household Balance Sheets," in Ben S. Bernanke and Julio J. Rotemberg, eds., NBER Macroeconomics Annual 1997, Cambridge, MA: MIT Press, pp. 165-217. 
[10] Carroll, Christopher D. and Samwick Andrew A. "The Nature and Magnitude of Precautionary Wealth." Journal of Monetary Economics, 1997, 40(1), pp. 41-72.

[11] Case, Karl E. "Real Estate and the Macroeconomy." Brookings Papers on Economic Activity, 2000, (2), pp. 119-162.

[12] Case, Karl E.; Quigley John M. and Shiller Robert J. "Comparing Wealth Effects: the Stock Market versus the Housing Market." Working Paper, Berkeley Program on Housing and Urban Policy, 2003.

[13] Chirinko, Robert S. "Business Fixed Investment Spending: A Critical Survey of Modelling Strategies, Empirical Results, and Policy Implications," Journal of Economic Literature, December 1993, 31(4), pp. 1875-911.

[14] Davis, Morris A. and Palumbo Michael. "A Primer on the Economics and Time Series Econometrics of Wealth Effects." Finance and Economics Discussion Series No. 9, Board of Governors of the Federal Reserve System, 2001.

[15] Diaz-Gimenez, Javier; Prescott Edward C.; Fitzgerald Terry and Alvarez Fernando. "Banking in computable general equilibrium economies." Journal of Economic Dynamics and Control, (16), pp. 533-559.

[16] Fisher, Irving. "The Debt Deflation Theory of Great Depressions." Econometrica, October 1933, (1), pp. 337-357.

[17] Fuhrer, Jeffrey. "Inflation/Output Variance Trade-Offs and Optimal Monetary Policy." Journal of Money, Credit and Banking, May 1997, 29(2), pp. 214-234.

[18] _ _ . "Habit Formation in Consumption and Its Implications for Monetary Policy." American Economic Review, June 2000, 90(3), pp. 366-390.

[19] Galí, Jordi. "On the Role of Technology Shocks as a Source of Business Cycles: Some New Evidence." Journal of the European Economic Association, April-May 2004, 2(2-3), pp. 372-380. 
[20] Galí, Jordi and Gertler Mark. "Inflation Dynamics: A Structural Econometric Analysis." Journal of Monetary Economics, October 1999, 44(2), pp. 195-222.

[21] Gilchrist, Simon and Leahy John V. "Monetary Policy and Asset Prices." Journal of Monetary Economics, January 2002, 49(1), pp. 75-97.

[22] Hansen Gary D. "Indivisible Labor and the Business Cycle", Journal of Monetary Economics, November 1985, 16(3), pp. 309-327.

[23] Higgins, Matthew and Osler Carol. "Asset Market Hangovers and Economic Growth: The OECD During 1984-93.” Oxford Review of Economic Policy, Fall 1997, 13(3), pp. 110-34.

[24] Hubbard, R. Glenn. "Capital-Market Imperfections and Investment." Journal of Economic Literature, March 1998, 36(1), pp. 193-225.

[25] International Monetary Fund. World Economic Outlook: Asset Prices and the Business Cycle, May 2000, Washington DC: International Monetary Fund.

[26] Ireland, Peter N. "A method for taking models to the data." Journal of Economic Dynamics E3 Control, 2004a, (28), pp. 1205-26.

[27] ___. "Technology Shocks in the New Keynesian Model." Review of Economics and Statistics, 2004b, forthcoming.

[28] Jappelli, Tullio and Pagano Marco. "Aggregate consumption and capital market imperfections: an international comparison." American Economic Review, December 1989, 79(5), pp. 1088-105.

[29] King, Robert G. and Wolman Alex. "Inflation Targeting in a St. Louis Model of the 21st Century." Federal Reserve Bank of St. Louis Review, May 1996, (78), pp. 83-107.

[30] Kiyotaki, Nobuhiro and Moore, John. "Credit Cycles." Journal of Political Economy, April 1997, $105(2)$, pp. 211-48.

[31] Lawrance, Emily C. "Poverty and the Rate of Time Preference: Evidence from Panel Data." Journal of Political Economy, February 1991, 99(1), pp. 54-77. 
[32] Levin, Andrew; Wieland, Volker and Williams, John C. "Robustness of Simple Monetary Policy Rules under Model Uncertainty,” in John B. Taylor, ed., Monetary Policy Rules. Chicago: University of Chicago Press, 1999. pp. 263-299.

[33] McCallum, Bennett T. "Issues in the Design of Monetary Policy Rules," in Handbook of Macroeconomics, in John B. Taylor and Michael Woodford, eds., Handbook of Macroeconomics, Vol. 1C. Amsterdam: North-Holland, 1999, pp. 1483-1503.

[34] Rotemberg, Julio J. and Woodford, Michael. "An Optimization-Based Econometric Framework for the Evaluation of Monetary Policy," in Ben S. Bernanke and Julio J. Rotemberg, eds., NBER macroeconomics annual. Cambridge and London: MIT Press, 1997, pp. 297-346.

[35] Samwick, Andrew A. "Discount rate heterogeneity and social security reform." Journal of Development Economics, October 1998, (57), pp. 117-146.

[36] Smets, Frank and Wouters Rafael. "Monetary Policy in an Estimated SDGE Model of the Euro Area." Journal of European Economic Association, September 2003, 1(5), 1123-75.

[37] Tobin, James. Asset Accumulation and Economic Activity. Oxford: Basil Blackwell, 1980.

[38] Uhlig, Harald. "A Toolkit for Analysing Nonlinear Dynamic Stochastic Models Easily," in Ramon Marimon and Andrew Scott (eds). Computational Methods for the Study of Dynamic Economies. Oxford: Oxford University Press, 1999, pp. 30-61.

[39] Zeldes, Stephen P. "Consumption and Liquidity Constraints: An Empirical Investigation." Journal of Political Economy, April 1989, 97(2), 305-346. 


\section{Tables}

\begin{tabular}{|c|c|c|}
\hline Description & Parameter & Value \\
\hline \multicolumn{3}{|l|}{ Preferences: discount factors } \\
\hline patient households & $\beta$ & 0.99 \\
\hline entrepreneurs & $\gamma$ & 0.98 \\
\hline impatient households & $\beta^{\prime \prime}$ & 0.95 \\
\hline \multicolumn{3}{|l|}{ Other preference parameters } \\
\hline weight on housing services & $j$ & 0.1 \\
\hline labor supply aversion & $\eta$ & 1.01 \\
\hline \multicolumn{3}{|l|}{ Technology: factors productivity } \\
\hline variable capital share & $\mu$ & 0.3 \\
\hline housing share & $\nu$ & 0.03 \\
\hline \multicolumn{3}{|l|}{ Other technology parameters } \\
\hline variable capital adjustment cost & $\psi$ & 2 \\
\hline variable capital depreciation rate & $\delta$ & 0.03 \\
\hline housing adjustment cost & $\phi$ & 0 \\
\hline \multicolumn{3}{|l|}{ Sticky prices } \\
\hline steady state gross markup & $X$ & 1.05 \\
\hline probability fixed price & $\theta$ & 0.75 \\
\hline
\end{tabular}

Table 1: Calibrated parameters in the extended model 


\begin{tabular}{lccc}
\hline \hline Description & Parameter & Value & s.e. \\
\hline Factor shares and loan-to-values & & & \\
patient households wage share & $\alpha$ & 0.64 & 0.03 \\
loan-to-value entrepreneur & $m$ & 0.89 & 0.02 \\
loan-to-value household & $m^{\prime \prime}$ & 0.55 & 0.09 \\
Autocorrelation of shocks & & & \\
inflation & $\rho_{u}$ & 0.59 & 0.06 \\
housing preference & $\rho_{j}$ & 0.85 & 0.02 \\
technology & $\rho_{A}$ & 0.03 & 0.10 \\
Standard deviation of shocks & & & \\
inflation & & & \\
housing preference & $\sigma_{u}$ & 0.17 & 0.03 \\
technology & $\sigma_{j}$ & 24.89 & 3.34 \\
\hline
\end{tabular}

Table 2: Estimated parameters and their standard errors in the extended model 


\section{Notes}

${ }^{1}$ With a slight abuse of notation, I use the terms "real estate", "assets" and "houses" interchangeably in the paper.

${ }^{2}$ See for instance International Monetary Fund (2000), Matthew Higgins and Carol Osler (1997), Karl Case (2000).

${ }^{3}$ In the VAR below I document a significant two-way interaction between house prices and GDP. Aggregate demand effects from changes in housing wealth have also been documented elsewhere; see for instance Case, John Quigley and Robert Shiller (2003).

${ }^{4}$ See for instance Jeffrey Fuhrer (2000), as well as the VAR evidence below.

${ }^{5}$ The Fed Funds rate is the average value in the first month of each quarter. The house prices series (deflated with the GDP deflator) is the Conventional Mortgage Home Price Index from Freddie Mac. The VAR included a time trend, a constant, a shift dummy from 1979Q4 and one lag of the log of the CRB commodity spot price index. Two lags of each variable were chosen according to the Hannah-Quinn criterion. The logs of real GDP and real house prices were detrended with a band-pass filter that removed frequencies above 32 quarters.

${ }^{6}$ Javier Diaz-Gimenez et al. (1992) use a similar device in an OLG model of the banking and household sector. I do not include imputed rents in my model definition of output. Doing so does not affect the results of the paper in any significant way. I also assume that housing and consumption are separable: Bernanke (1984) studies the joint behavior of the consumption of durable and non-durable goods and finds that separability across goods is a good approximation.

${ }^{7}$ Entrepreneurs are not risk neutral. Models of agency costs and business cycle typically assume risk neutral entrepreneurs. Carlstrom and Fuerst (2001) discuss the issue. In modeling firms' behavior in a model of monetary shocks, agency costs and business cycle, they consider two alternatives. In one, entrepreneurs are infinitely lived, risk neutral and more impatient than households: net worth sharply responds to shocks, as the elasticity of entrepreneurial savings to changes in the real rate of interest is 
infinite. In the other, a constant fraction of entrepreneurs die each period, so that net worth responds passively and slowly to changes in the real rate: in the aggregate, this is equivalent to a formulation in which entrepreneurs are extremely risk averse. Log utility can be considered as shorthand between these two extremes.

${ }^{8}$ With risk averse agents, nobody seems to get any benefit in terms of expected utility from lack of indexation: presumably, if contracts were indexed, there would be welfare gains. However, surprisingly few loan contracts are indexed in the United States, where even thirty year government and corporate bonds are not indexed. In Sections II.E and VI.A, I discuss how the results of the paper change when indexed debt is assumed.

${ }^{9}$ The Appendix is available on the AER website (http://www.aeaweb.org/aer/contents). Specifically, I construct a partial equilibrium model of consumption and housing choice which features an amount of volatility and a borrowing limit similar to that assumed here. There, I show that the conditions under which precautionary saving arises are very restrictive if the volatility is parameterized to reflect the amount observed in macroeconomic aggregates.

${ }^{10}$ The CES aggregate production function makes exact aggregation difficult. However, a linear aggregator of the form $Y_{t}^{f}=\int_{0}^{1} Y_{t}(z) d z$ equals $Y_{t}$ within a local region of the steady state. In what follows, I will consider total output as $Y_{t}$.

${ }^{11} \mathrm{~A}$ backward looking Taylor rule has the advantage of isolating in a neat way the exogenous component of monetary policy from its endogenous counterpart. As will be shown later, given that the interest rate is assumed to respond only with one lag to all other variables, it offers some convenient zero restrictions when taking the model to the data. Fuhrer (1997) shows that the data offer more support for a backward rule than for a forward rule. Bennett McCallum (1999) has emphasized a related point, since output and inflation data are reported with a lag and therefore cannot be known to the policymaker in the current quarter.

${ }^{12}$ The figure shows the cumulative drop in output after 40 quarters. This is approximately the horizon 
at which output has returned to the baseline, so that the cumulative impulse responses level off.

${ }^{13}$ It would be tempting to rank the two effects. However, there is no way of doing so: for instance, depending on how aggressive the central bank is on inflation, the debt deflation effect can be larger or smaller than the collateral effect.

${ }^{14} \mathrm{I}$ assume that the disturbance to $j_{t}$ is common to both impatient and patient households. This way, variations in $j_{t}$ can also proxy for exogenous variations in, say, the tax code that shift housing demand for all households.

${ }^{15}$ The money demand condition is redundant under interest rate control, so long as the central bank respects for each group the equality between money injections and transfers.

${ }^{16}$ Consistently with the theoretical model, I allow for all the variables (except the interest rate) to respond contemporaneously to a house price shock. The results were however robust to alternatively orderings. The lags and the set of exogenous variables are the same as in the VAR of Section I. Consumption, GDP and house prices were detrended with a band-pass filter removing frequencies above 32 quarters.

${ }^{17}$ The inflation shock shows up as a residual in the Phillips curve. It could be justified by assuming that the elasticity of demand for each intermediate good is time-varying, and varies exogenously, as done, for instance, by Frank Smets and Rafael Wouters (2003).

${ }^{18} \mathrm{~A}$ value of $\eta=1.01$ implies a virtually flat labor supply curve: this is higher than what microeconometric studies would suggest, but has the virtue of rationalizing the weak observed response of real wages to macroeconomic disturbances. With $\eta$ approaching 1 , the utility function becomes linear in leisure, as proposed and explained in Gary Hansen (1985).

${ }^{19}$ For the period 1974Q1-2003Q2, the standard deviation of (1) structures investment, (2) residential investment, (3) equipment \& software investment and (4) change in inventories are respectively 4.2, 6.5, 3.4 and 2.2 times that of GDP. (Inventories are computed as a fraction of GDP. The data were filtered 
using a band-pass filter that removed the low frequency component above 32 quarters.)

${ }^{20}$ The results with $\phi_{e}, \phi_{h}>0$ are qualitatively as follows: housing adjustment costs reduce the fluctuations in the housing stock variables but generate slightly larger changes in house prices and output, which the data appear to reject. Closer inspection of the impulse responses shows that, when facing costs of adjusting both $k$ and $h$, entrepreneurs vary labor input more strongly in response to disturbances, which in turn affects output.

${ }^{21}$ The standard deviation of the monetary shock $\sigma_{e}$ is taken from the standard error of the interest rate equation in the VAR below, which equals 0.29 . In principle, one could also obtain all the parameters of a more involved policy rule from the VAR. I use a shift dummy from 1979Q4 to capture monetary policy changes that are known to have occurred around that time.

${ }^{22} n=n_{1}^{2} \times n_{2}-n_{3}$, where $n_{1}$ is the number of variables in the VAR, $n_{2}$ are the elements to match for each impulse response, and $n_{3}$ are the elements of $\Psi$ which are zero by assumption (because of the zeros imposed by the Choleski ordering).

${ }^{23}$ As suggested by a referee, housing collateral is interesting because of the potential spillovers to other consumption goods as housing price increases relax borrowing constraints. By focusing on the parameters that best match the dynamic cross-correlation between house prices and output (and therefore consumption), the estimation procedure selects these particular moments as most informative at the margin for the values of $m, m^{\prime \prime}$ and $\alpha$.

${ }^{24}$ Standard errors were computed using the asymptotic delta function method applied to the first order condition associated with the minimization problem.

${ }^{25}$ These findings are robust to changes in the estimation horizon and in the weighting matrix. As a robustness check, I included the discount factors among the parameters to estimate. The resulting values for $\beta^{\prime \prime}$ and $\gamma$ were respectively around 0.4 and 0.9 ; the other parameter estimates were unchanged, with the exception of $m^{\prime \prime}$, whose estimate was marginally positive. Loosely speaking, a reduction in the discount factor works to strengthen the preference for current consumption, thus working in the same 
direction as an increase in the loan-to-value when it comes to explaining the high sensitivity of demand to aggregate shocks. However, although empirical estimates of the discount factor are surrounded by large uncertainty, values below 0.9 appear too low to be considered reasonable (see Carroll and Samwick, 1997).

${ }^{26}$ One caveat. The impulse responses from the VAR and those from the structural model are not strictly comparable, since the restrictions implied by the two representations are in general different. See Fuhrer (2000) for a discussion: an alternative could be to compare the autocorrelation functions implied by the various models. The results using this representation were qualitatively similar.

${ }^{27}$ Given the adjustment cost for capital, the initial response of output is roughly equal to that of consumption.

${ }^{28}$ One drawback of the model is that it predicts that households' housing holdings are countercyclical: with a fixed supply, this sector absorbs in fact the reduction in the demand by the entrepreneurs. This needs not to be unrealistic if housing is given a broad interpretation which also includes land. In Japan, for instance, households and the government have traditionally been net purchasers of land in periods of falling land prices (see the 2003 Annual Report on National Accounts of Japan).

${ }^{29} \mathrm{I}$ compute the Taylor curves tracing out the minimum weighted unconditional variances of output and inflation at different relative preferences for inflation versus output variance. I constrain interest rate volatility by imposing an upper bound 25 percent larger than the estimated standard deviation generated by the benchmark model. I also impose $r_{\pi}, r_{Y}>0$ to generate a unique rational expectations equilibrium for each policy.

${ }^{30}$ The "optimal" coefficients on output and inflation are larger than those estimated from the historical rule. If the relative weight on output stabilization is around, say, 10 percent, the optimal $r_{\pi}$ and $r_{Y}$ should be around 4 and 1.5 respectively. For this reason, the estimated policy rule indicated in the Figure performs worse than the optimal two-parameter rule for the model.

${ }^{31}$ In practice, a large response of the interest rate to the gap would stabilze the gap itself as well as 
inflation, but might violate the volatility bound on the interest rate: however, this could not hold under cost-push shocks, which would require either keeping inflation constant (but a large variance in the gap) or keeping the gap constant (but a large variance in inflation).

${ }^{32}$ In a variant of the model developed by Bernanke, Gertler and Gilchrist (1999) calibrated to UK data, Kosuke Aoki, James Proudman and Ian Vlieghe (2004) assess the impact of monetary policy on the real economy through its effect on consumption and housing prices. They however fall short of providing a full analysis of the interactions between house prices and the macroeconomy.

${ }^{33}$ The appendix is available on the AER website (http://www.aeaweb.org/aer/contexts).

${ }^{34}$ Carroll and Dunn (1997) develop a dynamic partial equilibrium model of consumption and debtfinanced housing purchases with idiosyncratic and aggregate uncertainty. They find that variations in uncertainty, combined with lumpy housing and transaction costs, can explain the timing of housing purchases over the cycle. Unlike theirs, my model, which does not have idiosyncratic risk, assumes that uncertainty is small and linearizes around the non-stochastic steady state. Despite these differences, my model also predicts that higher debt-to-income ratios (in the form of smaller down-payment constraints) may account for the increased sensitivity of expenditure to adverse (demand) shocks. 
Figures

FIGURE 1: VAR EVIDENCE, US

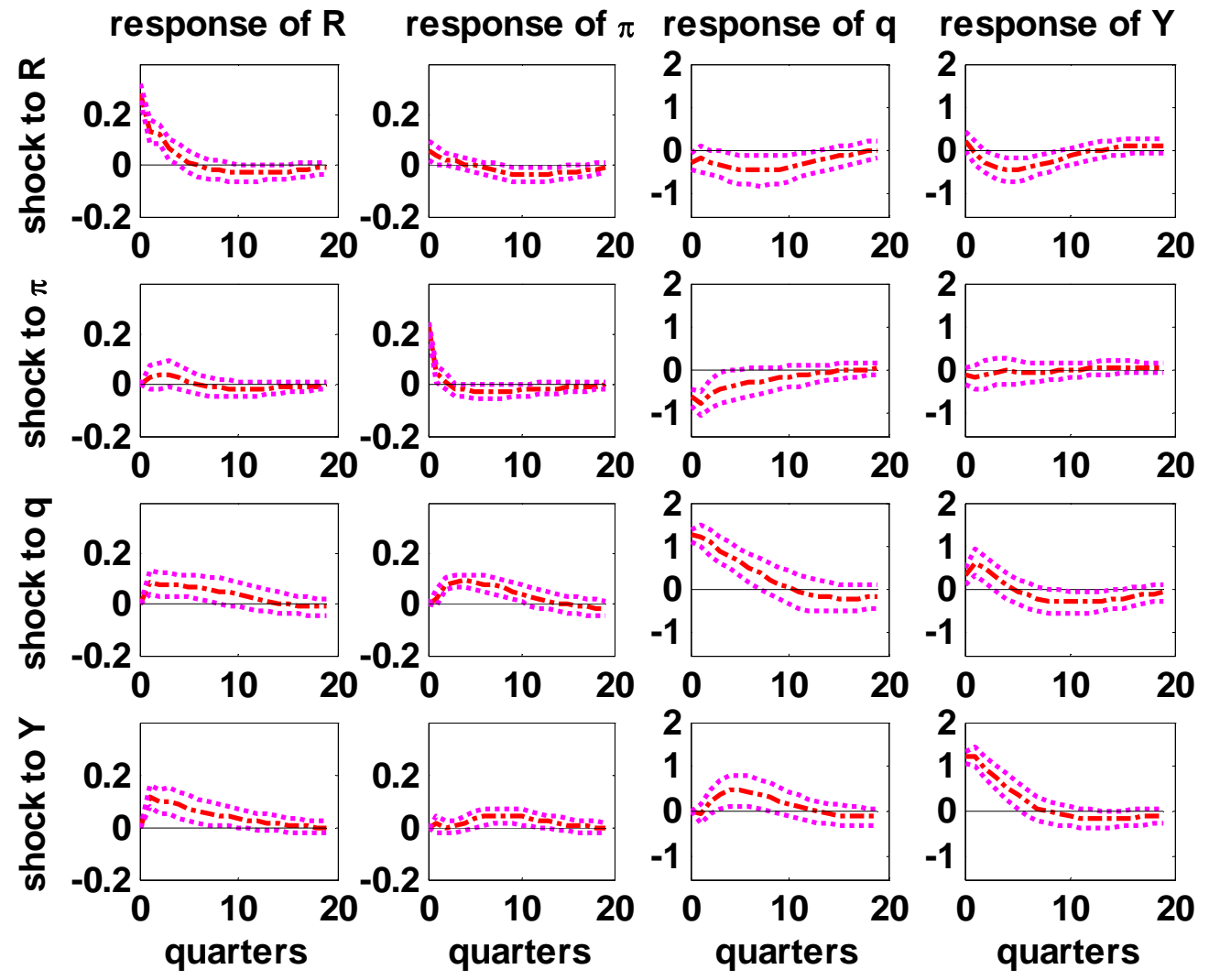

Notes: VAR estimated from 1974Q1 to 2003Q2. The dashed lines indicate 95 percent confidence bands. The Choleski ordering of the impulse responses is $R, \pi, q, Y$. Coordinate: percent deviation from the baseline. 
FIGURE 2: TOTAL OUTPUT LOSS IN RESPONSE TO A MONETARY SHOCK IN THE BASIC MODEL. COMPARISON BETWEEN ALTERNATIVE MODELS

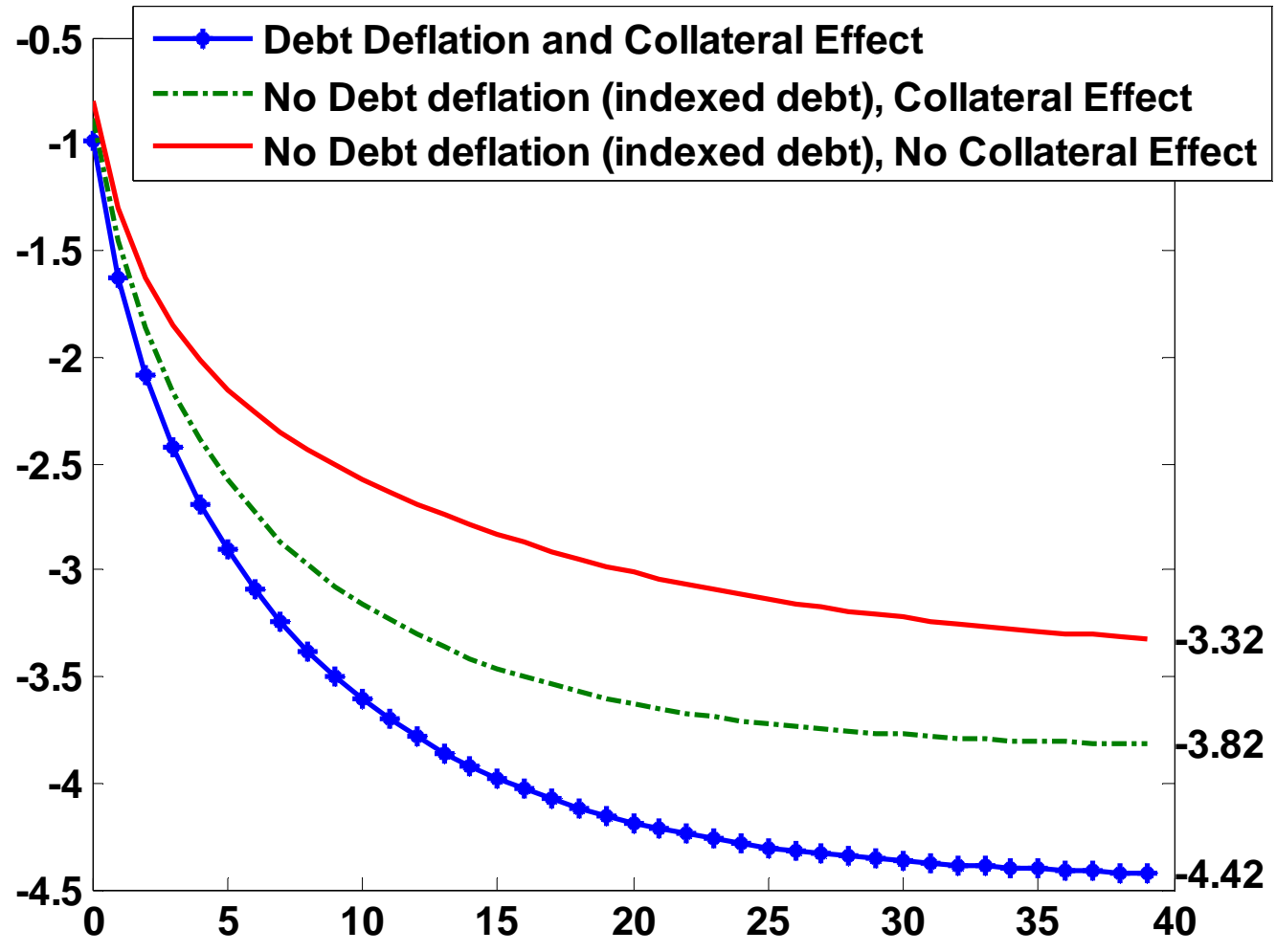

Notes: Ordinate: Time Horizon in Quarters. Coordinate: percent deviation from initial steady state. 
FIGURE 3: RESPONSE OF AGGREGATE CONSUMPTION TO A HOUSE PRICE SHOCK VARIOUS VALUES OF $m$ AND $m$ "
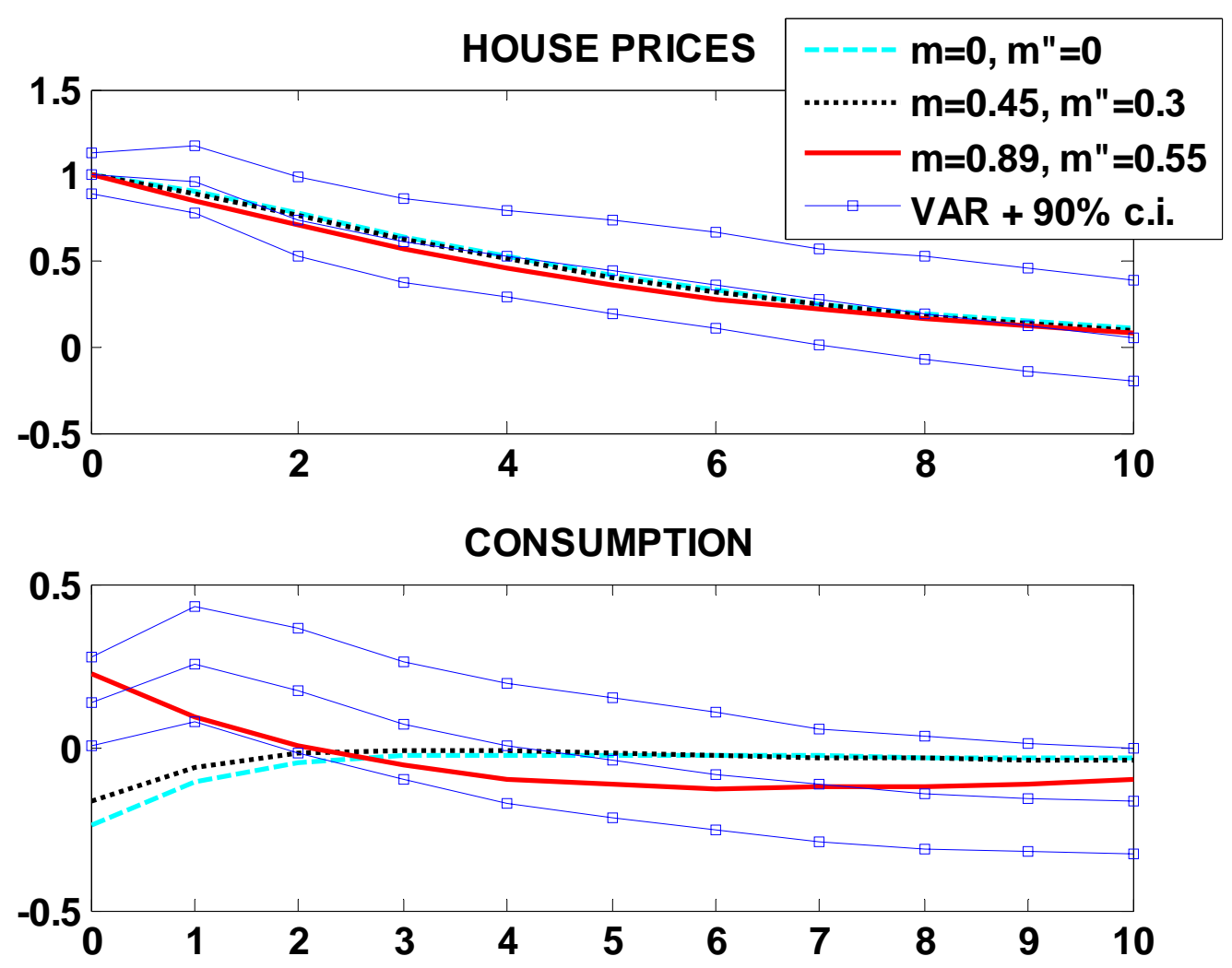

Notes: Ordinate: Time Horizon in Quarters. Coordinate: percent deviation from initial steady state. 
FIGURE 4: RESPONSE OF OUTPUT TO AN INFLATION SHOCK

NOMINAL VERSUS INDEXED DEBT
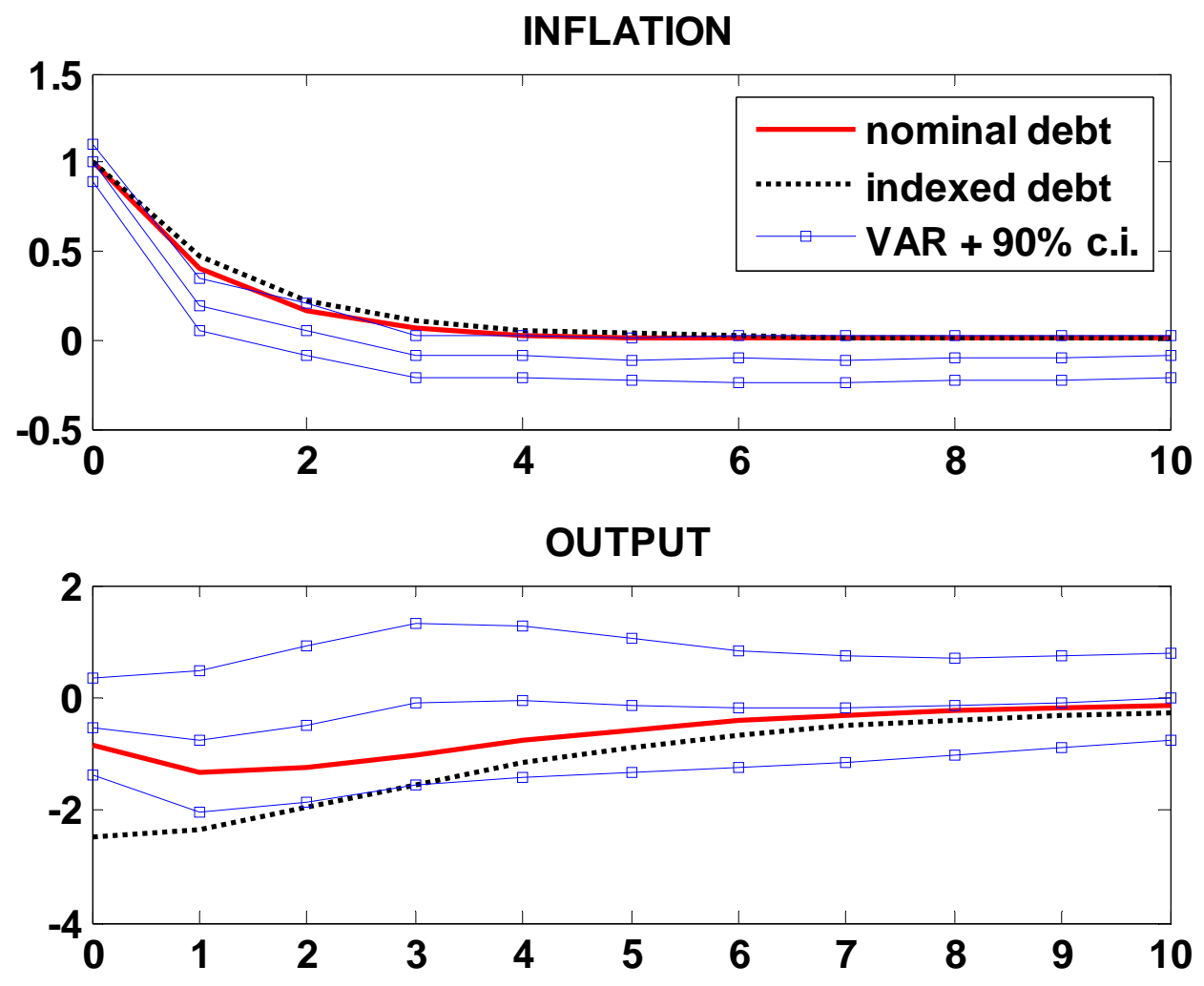

Notes: Ordinate: Time Horizon in Quarters. Coordinate: percent deviation from initial steady state. 
FIGURE 5: RESPONSES TO ALL SHOCKS, MODEL VS VAR

(Solid lines: estimated model, dotted lines: VAR model with 90 percent bands)
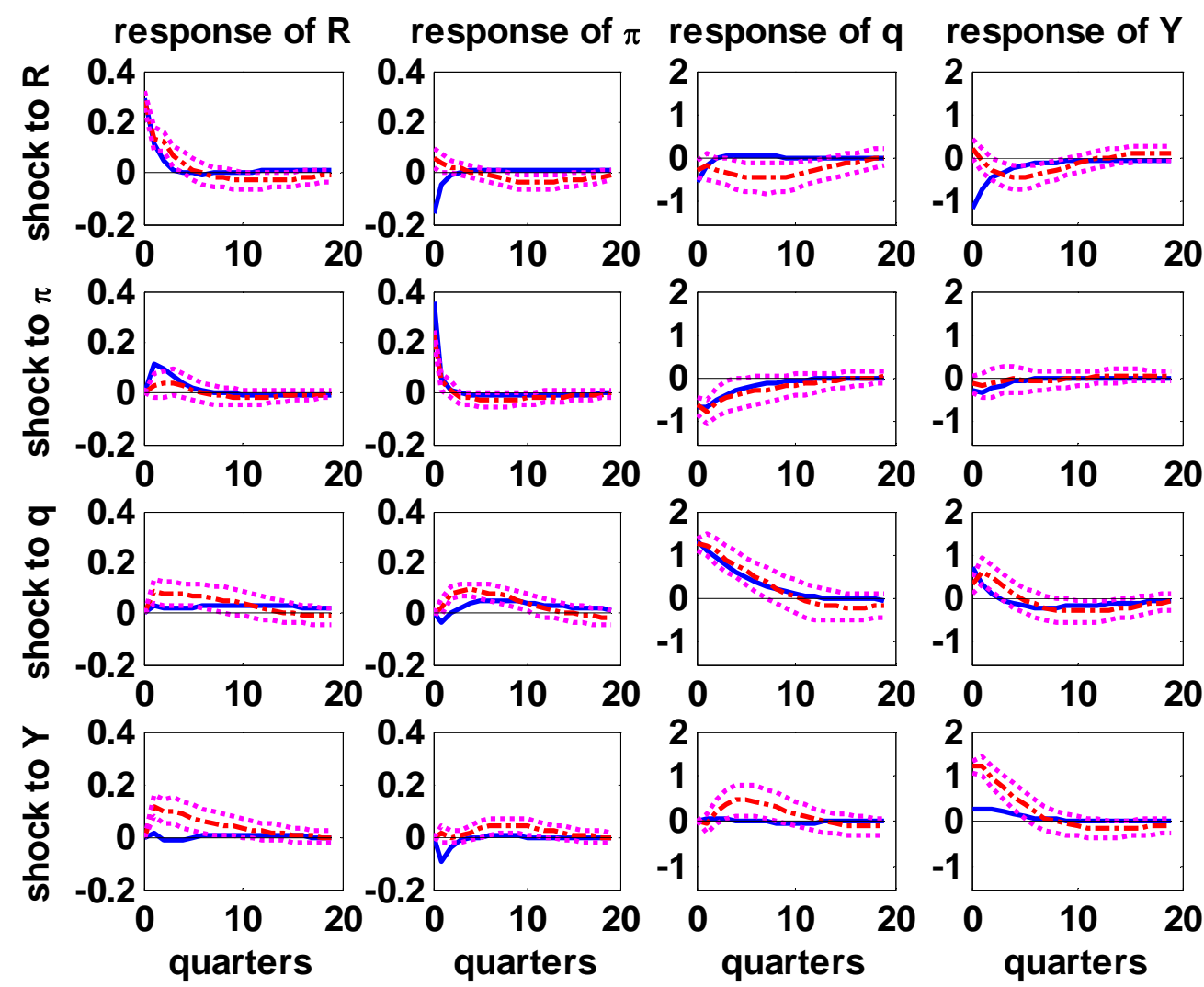

Note: Coordinate, percent deviation from steady state. 
FIGURE 6: POLICY FRONTIERS AND ASSET PRICE RESPONSES

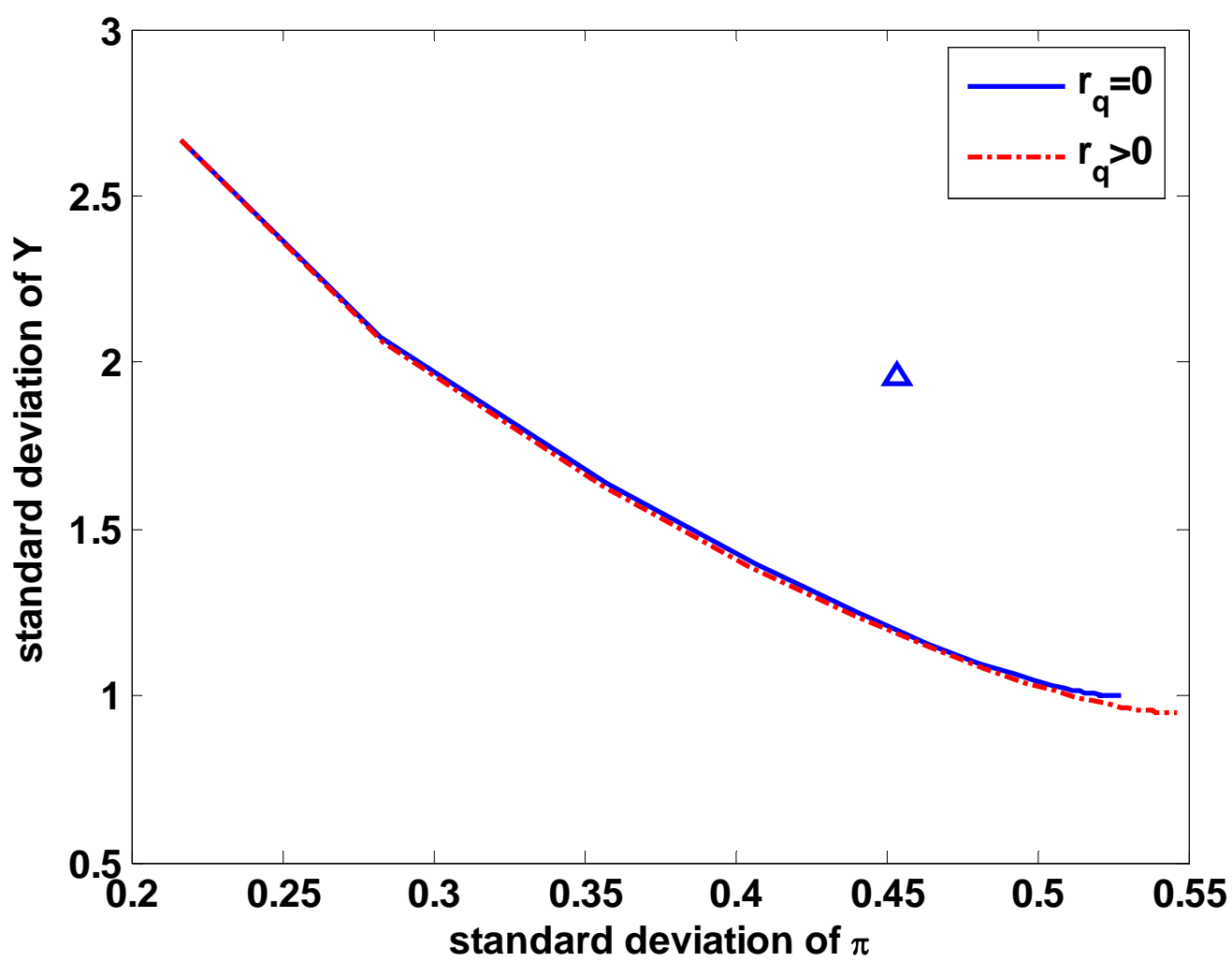

Note: the triangle indicates the performance of the rule estimated for the period 1974Q1$2003 \mathrm{Q} 2$. 
FIGURE 7: POLICY FRONTIERS: NOMINAL VERSUS INDEXED DEBT

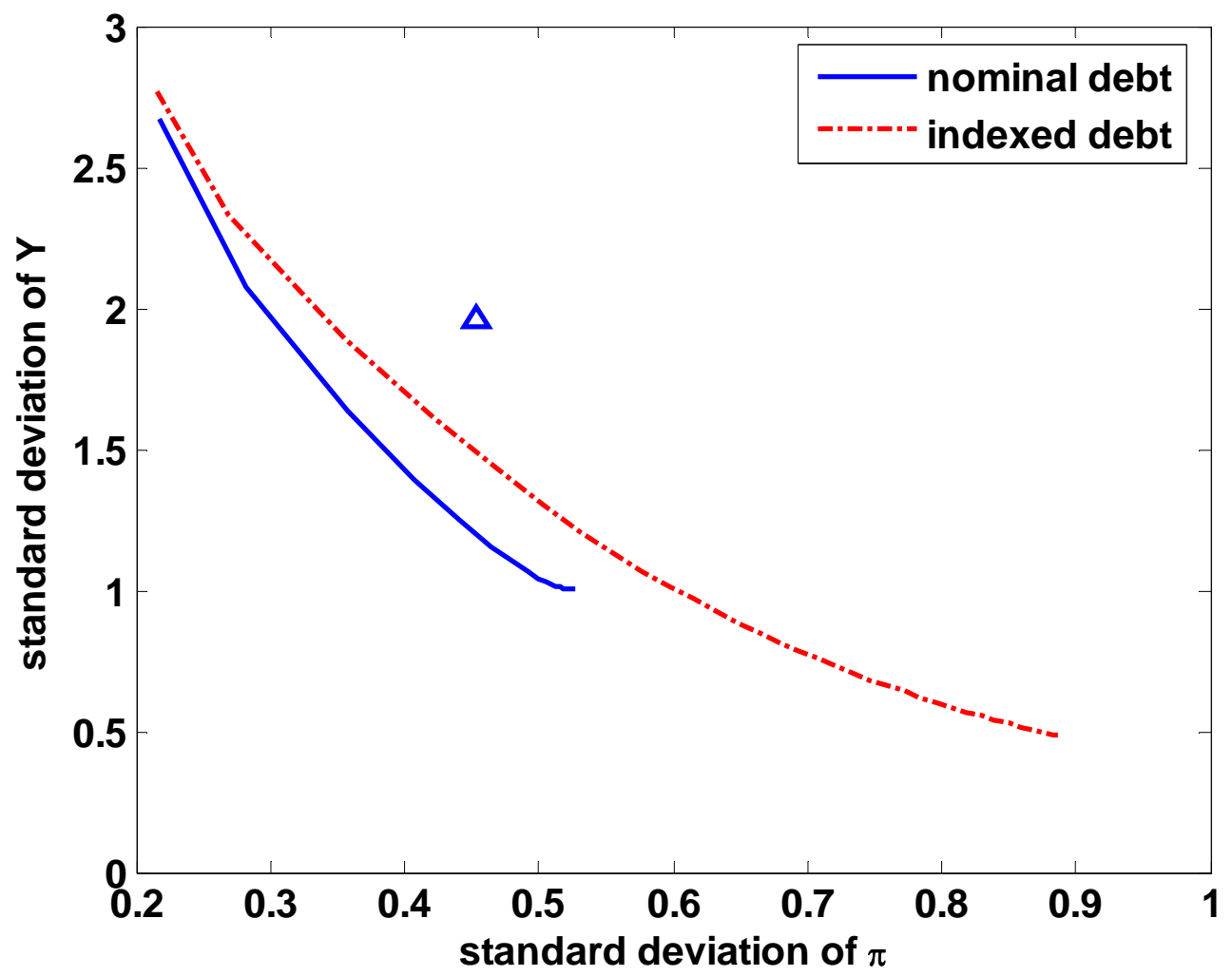

Note: the triangle indicates the performance of the rule estimated for the period 1974Q1$2003 \mathrm{Q} 2$. 
FIGURE 8: POLICY FRONTIERS WITH OUTPUT GAP

NOMINAL VERSUS INDEXED DEBT

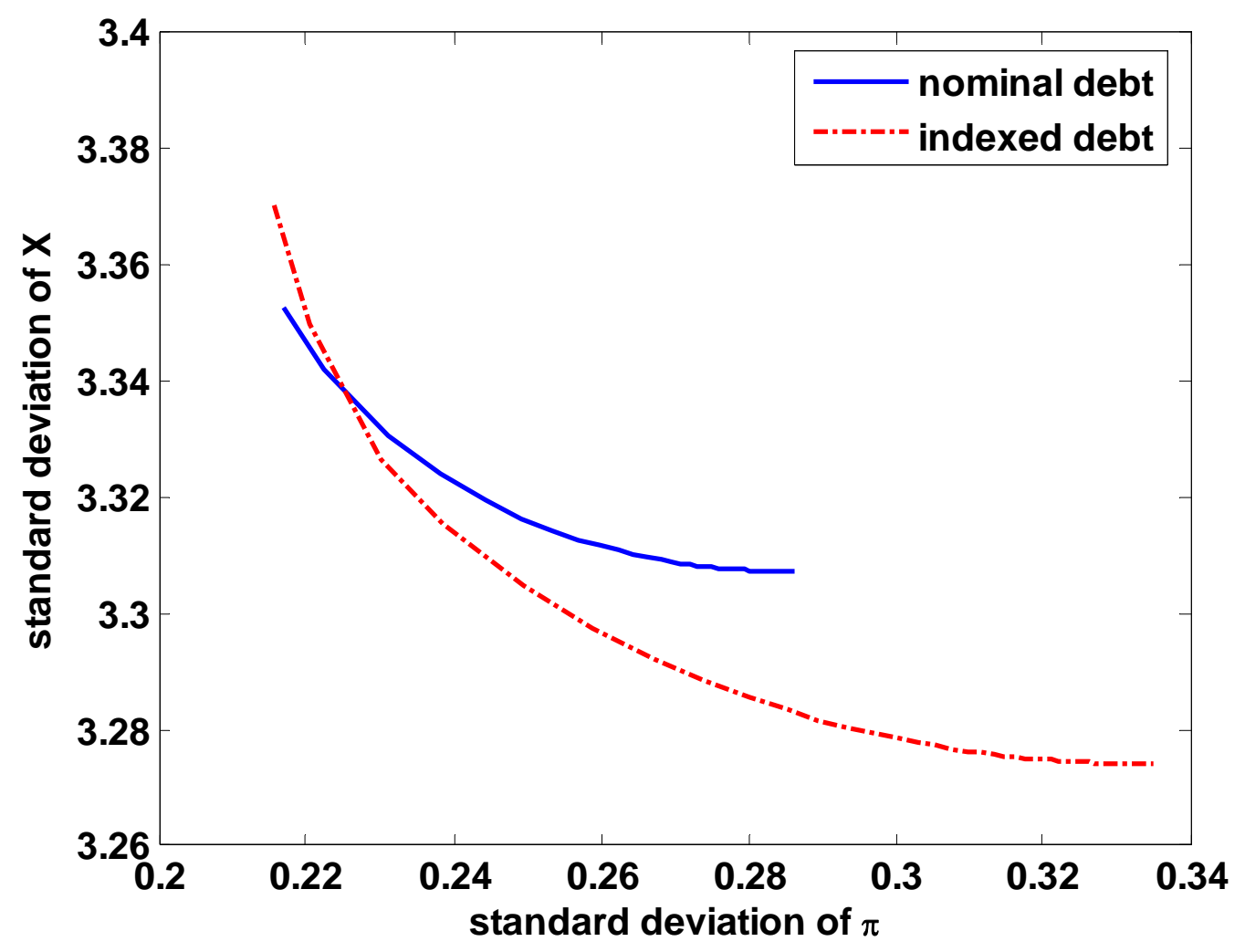




\section{Appendix C to "House Prices, Borrowing Constraints and Monetary Policy in the Business Cycle".}

December 3, 2004

Matteo Iacoviello

iacoviel@bc.edu

\section{Consumption and housing choice with borrowing constraints: when do constraints binds?}

In this appendix, I sketch the partial equilibrium problem of an infinitely-lived household that maximizes expected intertemporal utility. The household derives utility from the non-durable consumption $c$ and from housing $h$. The household faces a budget constraint and a borrowing constraint tied to a fraction of the value of the durable asset. Income is produced according to a production function that can potentially take housing as input. The productivity variable is random and follows an $A R(1)$ process.

The main result of this appendix is that, when the model is parameterized with an amount of uncertainty that is sufficient to replicate the volatility which is observed in macroeconomic time series, such uncertainty is "too small" to generate a substantial amount of buffer-stock behavior in the model (loosely meant as borrowing less than the credit limit), provided that the borrowing constraint is tight enough ( $m$, the loanto-value ratio, is not too high), that relative risk aversion is not too large, that the gap between the interest rate and the discount rate is not too small. ${ }^{1}$

\section{The model setup}

I consider the partial equilibrium problem of optimal consumption and savings behavior of an agent who maximizes the discounted sum of future utility subject to an asset accumulation constraint and to a borrowing constraint tied to asset holdings up to a fraction $m$, which I call the loan-to-value ratio. I assume zero depreciation for the durable asset. ${ }^{2}$ I assume that the interest rate is exogenous and lower than the time preference rate (otherwise, asset accumulation would converge to infinity, as shown by Gary Chamberlain and Charles Wilson, 2000).

My interest is in understanding which conditions are needed for such a model to generate instances in which the borrowing constraint does not hold with equality.

I consider the problem of a representative agent that maximizes expected discounted utility from consumption of both a nondurable good $c_{t}$ and a durable asset $h_{t}$. The lifetime utility function is of the form:

$$
\begin{aligned}
U & =E_{0}\left(\sum_{t=0}^{\infty} \beta^{t} \frac{\left(c_{t} h_{t}^{j}\right)^{1-\rho}-1}{1-\rho}\right) \text { when } \rho>0, \rho \neq 1 \\
U & =E_{0}\left(\sum_{t=0}^{\infty} \beta^{t}\left(\log c_{t}+j \log h_{t}\right)\right) \text { when } \rho=1
\end{aligned}
$$

\footnotetext{
${ }^{1}$ Of course, the presence of uncertainty implies that in a model of the kind presented below there is precautionary saving, meant as the extra-increase in average total wealth (housing wealth less total outstanding debt, that is $h-b$ ) due to income uncertainty. What I am mainly interested in, however, is whether the model parameters generate fluctuations in the ratio between borrowing and housing $(b / h)$.

${ }^{2}$ Allowing for positive depreciation does not affect the main results.
} 
In the paper, I assume that relative risk aversion is 1 , so that log utility and separability arise. The budget constraint is:

$$
c_{t}=y_{t}+b_{t}-R b_{t-1}-\left(h_{t}-h_{t-1}\right)
$$

where income is $y_{t}=A_{t} h_{t-1}^{\nu}$ and the borrowing constraint is:

$$
b_{t} \leq m h_{t} .
$$

One can interpret (apart from minor differences) this formulation as a simplified version of the impatient agents' problem in the paper when the following conditions hold: (1) prices are constant; (2) the interest rate is constant and higher than the discount rate; (3) the asset price is constant.

The stochastic process for $A_{t}$ obeys the following:

$$
\log \left(A_{t}\right)=0.75 \log \left(A_{t-1}\right)+e_{t}, e_{t} \sim N\left(0, \sigma_{e}^{2}\right)
$$

Fluctuations in $A$ are therefore the only source of randomness in the model. ${ }^{3}$ Altogether there are three state variables: $\left(h_{t-1}, b_{t-1}, A_{t}\right)$.

The model is calibrated at quarterly frequencies. For expositional reasons, I keep the model formulation similar to the problem of the constrained households in the paper, by setting the following baseline parameters: $\nu=0, j=0.1, m=0.55, R=1.01, \beta=0.95$. This way, the problem boils down to the problem of choice between consumption and a durable good in the presence of stochastic income, and the durable asset only provides utility services, without affecting total income produced. ${ }^{4}$

I experiment with several values for the $\sigma_{e}$, the conditional variance of income. In the estimated general equilibrium model of the paper, the unconditional standard deviation of quarterly detrended output is about 2 percent, which is roughly the value found in the data. A value of $\sigma_{e}=0.013$ (which generates an unconditional standard deviation for $A$ of $\left.\sigma_{A}=0.0197\right)$ is what is needed to roughly replicate aggregate volatility.

A model of this kind is fairly standard in partial equilibrium analyses of consumer behavior in presence of uncertainty, see e.g. Christopher Carroll (2000) or Sydney Ludvigson (1999). Ludvigson, for instance, assumes no capital, but ties borrowing to aggregate income and assumes that $m$ is time-varying. Unlike traditional analyses, however, the model assumes that the investment good is both a productive asset and collateral for loan. To experiment for variable (shadow) price of the asset, I also tried versions of the above model with quadratic adjustment costs: most of the results presented below resulted to be robust to this change.

The question I want to address is: under which conditions does the model generate borrowing constraints which do not bind?

\footnotetext{
${ }^{3}$ In the model of the paper, the quarterly theoretical autocorrelation of output is 0.65 . In the (band-pass filtered) data, the autocorrelation of GDP is 0.86 . Here, I set the autoregressive component of the only driving process for output at the average between these two values.

${ }^{4}$ I consider several values for the standard deviation of the innovation process. I approximate this process by using a five state Markov chain following the procedures described in George Tauchen (1986). I discretize the state space for the two states, housing and debt, using a $40 \times 40$ grid for the two variables with a uniform range that takes values from 20 percent less to 20 percent more than their steady state, non-stochastic values. In the simulations below, the bounds on $h$ are very rarely binding. Such bounds $h$ are also in accordance with the set-up of the paper in which the supply curve for housing is not flat.
} 


\section{Does the collateral constraint always bind?}

A solution for the above problem can be summarized by a consumption rule $c_{t}=c\left(A_{t}, h_{t-1}, b_{t-1}\right)$, an asset accumulation rule $h_{t}=h\left(A_{t}, h_{t-1}, b_{t-1}\right)$ and a borrowing rule $b_{t}=b\left(A_{t}, h_{t-1}, b_{t-1}\right)$. After such a solution is found, I use these decision rules to generate time profiles for the model variables.

Figure A.1 presents the results for the baseline case, showing a simulation of income $y_{t}$, consumption $c_{t}$ and borrowing $b_{t}$ over housing for 500 periods. Here, the borrowing constraint is binding 100 percent of the times. As a consequence, consumption closely tracks income, in good as in bad times. ${ }^{5}$ On average, consumption is lower than income, since the individual ends up with a positive amount of debt to roll over on which interest is paid.

In Figure A.2, I consider a different example in which relative risk aversion is raised to $\rho=5$ and the standard deviation of the innovation in productivity is $\sigma_{e}=0.05 .{ }^{6}$ Here, buffer stock behavior emerges, and liquidity constraints bind less often. After a sufficiently long run of income shocks, the debt/asset ratio falls below the maximum loan-to-value (bottom panel). Although consumption continues to track income closely, the decision rules highlight the role played by precautionary behavior: liquidity constrained periods, in particular, are 76.8 percent of the total.

In general, there are four parameters that affect how often borrowing constraints bind. (1) The degree of risk aversion; (2) the volatility of the underlying income process; (3) the loan-to-value ratio; (4) the gap between the interest rate and the discount rate. How does each of these factors contribute?

In Figure A.3, I keep $\beta=0.95$ and $m=0.55$, as in the baseline case, and calculate the fraction of liquidity constrained periods as a function of risk aversion and income variability. ${ }^{7}$ Not surprisingly, the borrowing constraint binds less frequently as risk aversion rises, and the effect is stronger when risk aversion is large.

For log utility, in fact, (relative risk aversion of $\rho=1$ ), the borrowing constraint binds 100 percent of the cases if $\sigma_{e} \leq 0.06$ : such a number would correspond to an unconditional standard deviation of aggregate income about four times larger than needed to replicate macroeconomic volatility. It takes very high risk aversion coupled with very high volatility to have precautionary behavior.

In Figure A.4, I consider how the frequency of borrowing constrained periods depends on $m$. To begin, in the baseline calibration for $\beta, \rho$ and $\sigma_{e}$, the borrowing constraint holds 100 percent regardless of the value of $m$. If income volatility $\sigma_{e}$ is raised from its baseline value of 1.3 percent to 5 percent, borrowing constraints are less likely to bind the higher $m$ is. When risk aversion and income variability are high, the effect is stronger the higher is $\beta .^{8}$

I therefore conclude that for a wide range of parameter configurations the assumption that the borrowing

\footnotetext{
${ }^{5}$ Consumption does not track income exactly because the household can use both consumption and housing to smooth utility. For instance, in response to, say, a positive income shock, the household, ceteris paribus, increases both consumption and housing holdings, so that consumption rises less than one for one with income. The possibility to borrow more following the increase in $h$ further increases consumption and housing demand, but the total effect is that consumption is slightly smoother than income.

${ }^{6}$ I keep the discount factor unchanged at $\beta=0.95$. Increasing the discount factor reduces the impatience motive and increases the need to accumulate assets, but at the same time changes the non-stochastic steady-state.

${ }^{7}$ In the simulations below I include 5500 periods, and discard the first 500 observations.

${ }^{8}$ In general, the discount factor has little effect on the results: so long as $1 / \beta$ stays above $R$, the borrowing constraint is binding in 100 percent of the cases. Keeping the other parameters of the baseline calibration unchanged, the borrowing constraint binds less than 100 percent only if $\beta$ is greater than around 0.986 .
} 
constraint always holds is a very good approximation. In my view, there are two explanations for this result:

1. A representative agent model rules out the much larger idiosyncratic risk which instead is needed to replicate the microeconomic evidence on income volatility. For instance, Carroll and Wendy Dunn (1997) obtain buffer-stock effects because of the probability of unemployment that each agent faces.

2. Another potential explanation is related to studies that find a modest effect of income uncertainty on capital accumulation in the stochastic growth model (see Carroll (2000) for an example): there, little precautionary saving arises because the representative agent in the model has a large amount of capital. Here, the borrowers tend to overinvest in capital for two additional reasons: (1) durable assets reduce the need to hold a buffer stock of resources to shield consumption from income risk; in addition, (2) agents here "overinvest" in durable assets because they can loosen the borrowing constraint: once they do so, they end up with a very large amount of wealth, therefore the need to borrow less than the maximum possible amount becomes small. ${ }^{9}$

\section{Caveats}

The results here are obtained in a partial equilibrium context and without endogenizing the price of the durable asset. What happens, instead, if the price of the asset is endogenous? Here, I provide an intuitive answer to that question.

The key to understanding the behavior of the model when the housing supply curve is not flat is that, when the demand rises (in good times), the price of the collateral will go up: this will have two effects. The price effect works to reduce asset demand. The collateral effect drives asset demand up, leading to further relaxation of the borrowing constraint. If the second effect dominates, the collateral capacity for each unit of the asset pledged becomes procyclical, rising in good times, falling in bad times. This suggests that borrowing constraints might become "looser" in good times, thus offering potential for more buffer-stock behavior in good times, and for less in bad times. If so, borrowing constraints might be less likely to bind in good states of the world.

However, given the assumptions about the model parameters, this outcome seems unlikely in the baseline scenario. In the paper, for instance, asset price fluctuations are roughly of the same magnitude as the fluctuations in productivity. In the baseline case, whether borrowing constraints bind or not is insensitive to the value of $m .{ }^{10}$ One can thus infer that even if asset prices were to change dramatically over the cycle, collateral constraint would always bind in the baseline case. This lends indirect support to the assumption that low uncertainty and small curvature of the utility function are sufficient to guarantee that the borrowing constraint is always binding over the relevant range.

\footnotetext{
${ }^{9}$ A similar result is obtained by Antonia Díaz and Maria Luengo-Prado (2003): they find that the presence of collateralizable durable goods reduces the need for precautionary saving in an otherwise standard income fluctuation problem. In a similar vein, using a partial equilibrium model of consumption and mortgage choice under uncertainty, Erik Hurst and Frank Stafford (forthcoming) show how housing wealth can effectively be used as a hedge against adverse economic shocks.

${ }^{10}$ Quantitatively, an increase in $m$ in the household problem leads to a reduction of the frequency of binding borrowing constraints only if high income volatility is coupled with a very high discount factor. Results are slightly different in the entrepreneurial problem instead: over a plausible range of parameters, an increase in $m$ is likely to lead to an increase in buffer-stock behavior.
} 
In experiments not reported here, I set $j=0$ and allow for $\nu>0$. With this modification, the problem becomes similar to that faced by the entrepreneur, since housing enter the production rather than the utility function. I find that, ceteris paribus, the entrepreneurial problem results in slightly larger (but not significantly different) buffer-stock behavior than the household problem: this happens because, when housing is needed to produce the consumption good (rather than to provide utility services), it can be used less effectively to smooth out income fluctuations, thus increasing the need not to use all the borrowing capacity during good times. ${ }^{11}$

\section{References}

[1] Carroll, Christopher D. "Requiem for the Representative Consumer? Aggregate Implications of Microeconomic Consumption Behavior," American Economic Review, May 2000 (Papers and Proceedings), pp. $110-115$

[2] Carroll, Christopher D. and Dunn Wendy D. "Unemployment Expectations, Jumping (S,s) Triggers, and Household Balance Sheets," in Ben S. Bernanke and Julio J. Rotemberg, eds., NBER Macroeconomics Annual 1997, Cambridge, MA: MIT Press, pp. 165-217.

[3] Chamberlain Gary and Wilson Charles A. "Optimal Intertemporal Consumption Under Uncertainty", Review of Economic Dynamics, July 2000, 3(3), pp. 365-395.

[4] Díaz, Antonia and Luengo-Prado Maria J. "Precautionary Savings and Wealth Distribution with Durable Goods". Working Paper, Universidad Carlos III de Madrid and Northeastern University, 2003.

[5] Hurst, Erik, and Stafford Frank. "Home Is Where the Equity Is: Mortgage Refinancing and Household Consumption." Journal of Money, Credit and Banking, forthcoming.

[6] Ludvigson, Sydney. "Consumption and Credit: A Model of Time-Varying Liquidity Constraints." The Review of Economics and Statistics, August 1999, 81(3), pp. 434-47.

[7] Tauchen, George. "Finite State Markov-Chain Approximations to Univariate and Vector Autoregressions," Economics Letters, 1986, (20), pp. 177-81.

\footnotetext{
${ }^{11}$ For instance, if $\sigma_{e}=0.05, \beta=0.95, \rho=5, m=0.55, j=0$ and $\nu=0.0919$, we have the same steady state housing holdings and debt as in the household problem (where $\nu=0$ and $j=0.1$ ). However, the frequency of binding borrowing constraints is 75.5 percent, as opposed to 76.8 percent in the household problem.
} 
Figures

Figure A.1: Simulated Variables, Baseline Case
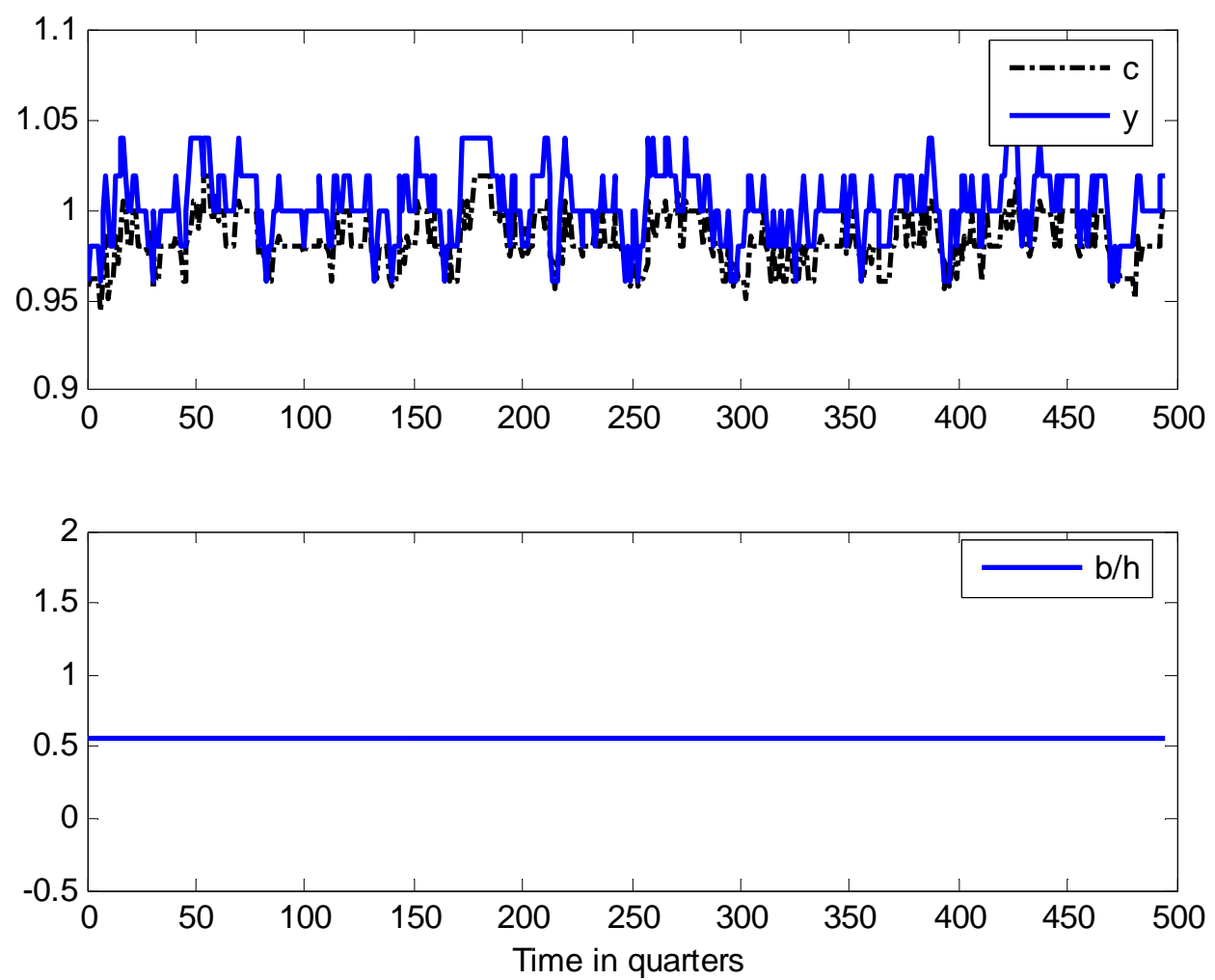
Figure A.2: Simulated Variables, High Volatility, High Discount Factor, And High Risk Aversion.
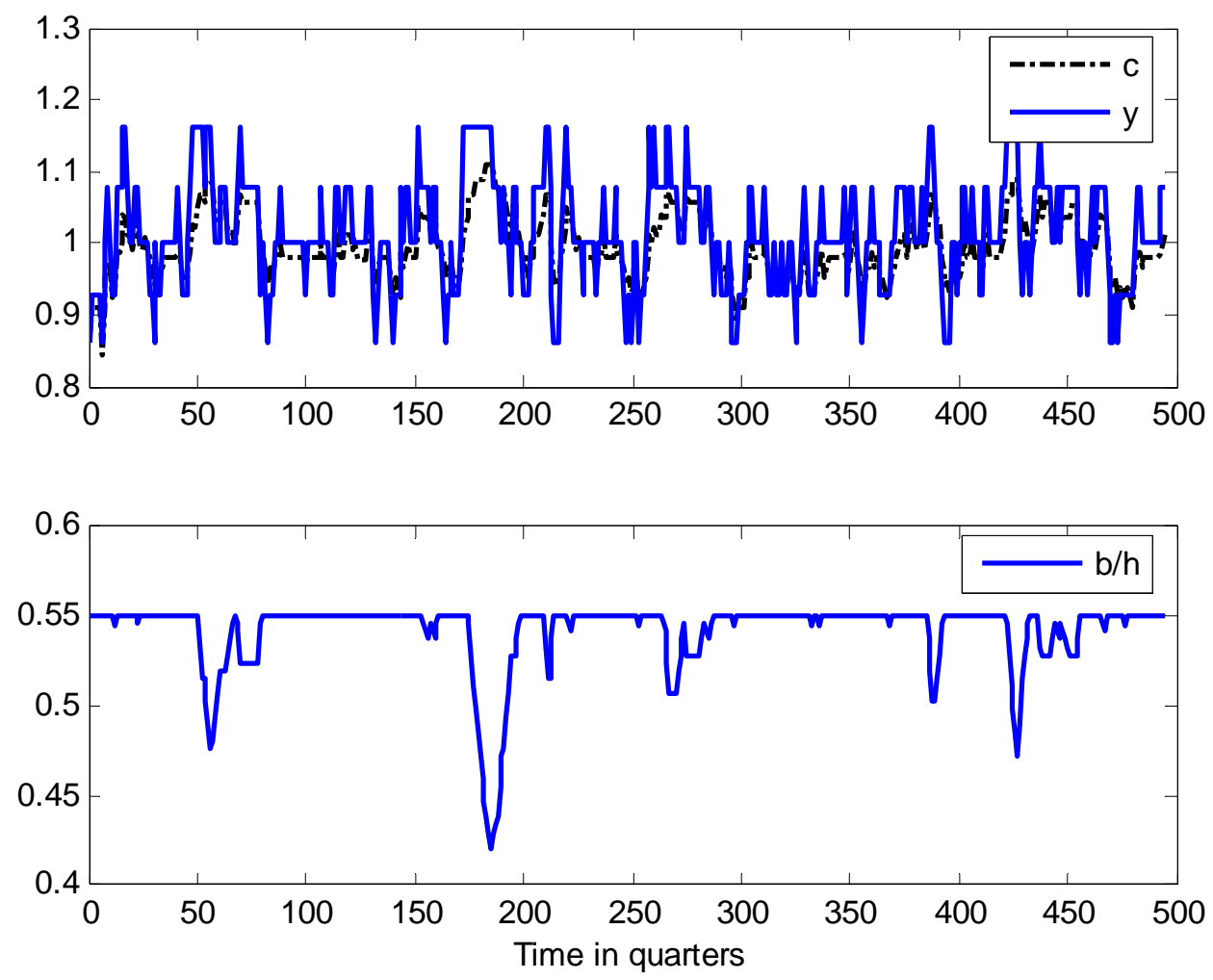
Figure A.3: Frequency Of Times The Borrowing Constraint Binds As A Function Of The Volatility For Different Degrees Of Risk Aversion.

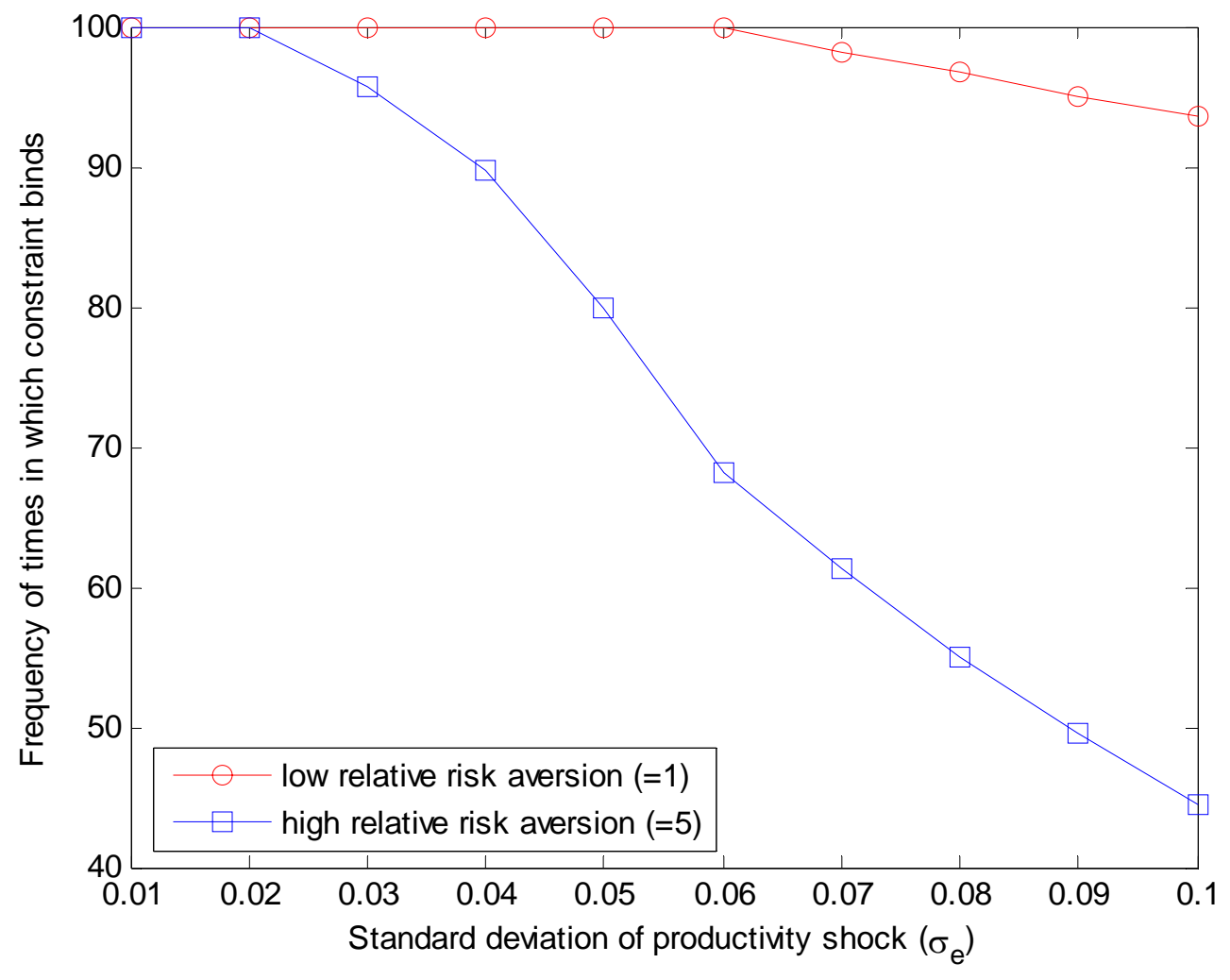


Figure A.4: Frequency Of Times The Borrowing Constraint Binds As A Function Of The LoanTo-Value m, For Different Values Of The Other Parameters.

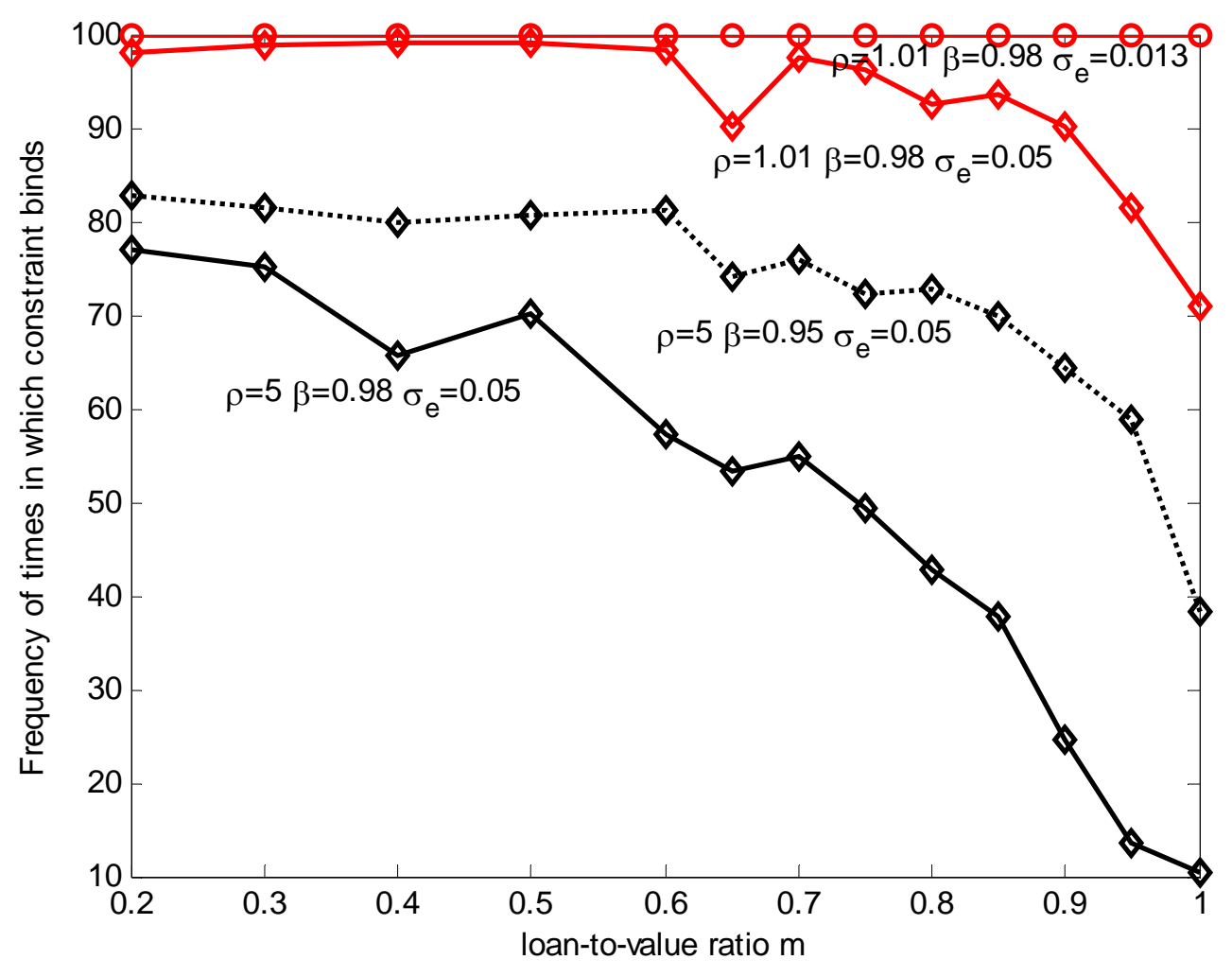

